\title{
Las ocupaciones paracas y topará en Cerro del gentil, VAlle De Chincha
}

\author{
Henry Tantaleán ${ }^{a}$, Charles Stanish ${ }^{b}$, Kelita Pérez ${ }^{c}$ y Alexis Rodríguez ${ }^{d}$
}

\section{Resumen}

En este articulo, presentamos una sintesis de las principales evidencias arqueológicas recolectadas durante nuestras tres últimas temporadas de investigación en el sitio de Cerro del Gentil, ubicado en el valle medio de Chincha, costa sur del Perú. A partir de estas evidencias, planteamos una serie de prácticas sociales que se habrian dado en este sitio y sus implicancias para la explicación de las ocupaciones humanas asociadas con las tradiciones Paracas y Topará en el valle de Chincha entre los siglos VI y II a.C.

Palabras clave: costa sur del Perú, valle de Chincha, Paracas, Topará, Cerro del Gentil, ritual

\section{Abstract}

\section{PARACAS AND TOPARÁ OCCUPATIONS IN CERRO DEL GENTIL, CHINCHA VALLEY}

This article presents a synthesis of the principal archaeological evidence obtained during the last three field seasons at the site of Cerro del Gentil in the middle Chincha Valley on Peru's south coast. Based on these data, we propose the existences of a series of social practices that were conducted at the site. We further explore the implications of these results for understanding the Paracas and Topara occupations in the Chincha valley between the 6th and 2nd centuries BCE.

Keywords: Peruvian southern coast, Chincha valley, Paracas, Topará, Cerro del Gentil, ritual

a Cotsen Institute of Archaeology e Instituto Francés de Estudios Andinos, Lima

Correo electrónico: henrytantalean@yahoo.es

b Cotsen Institute of Archaeology y Santa Fe Institute, Santa Fe, New Mexico

Correo electrónico: stanish@ucla.edu

c Programa de Estudios Andinos, Pontificia Universidad Católica del Perú

Correo electrónico: kelitacubas@yahoo.es

d Universidad Nacional Mayor de San Marcos, Escuela Profesional de Arqueología

Correo electrónico: alexisrodriguezyabar@gmail.com 


\section{Introducción}

El sitio arqueológico de Cerro del Gentil está conformado por un conjunto de edificios construidos principalmente durante el Período Paracas Medio y Tardío (600 a 200 a.C.). El edificio principal (Edificio 1) funcionó originalmente como el escenario de rituales dirigidos por los líderes paracas del valle de Chincha. Su construcción se inició a mediados del siglo VI a.C. y fue concebido como un proyecto que estuvo vinculado con otras construcciones similares en el valle bajo. A su vez, el edificio tuvo como componente principal un patio hundido de forma cuadrangular. Nuestras excavaciones revelaron la existencia de tres grandes fases arquitectónicas en la vida del Edificio 1 . La primera fase estuvo relacionada con la configuración y construcción del edificio que incluyó, al menos, un primer patio hundido. La segunda fase replicó la forma de ese primer patio hundido a menor escala, adosándolo sobre las paredes del antiguo. La tercera reconstrucción modificó la forma y función original del patio hundido.

Aproximadamente, en el siglo III a.C., las funciones originales del edificio terminaron y el interior del patio hundido atravesó por un proceso de sellado con el depósito de varias capas de tierra mezcladas con artefactos, enterramiento de ofrendas y desechos durante un período de tiempo relativamente corto. Poco tiempo después, se construyó una plataforma de piedra y tierra sobre la parte central del edificio paracas, vinculada con arquitectura y material topará.

En este artículo, además de la presentación de una importante cantidad de evidencias arqueológicas, también planteamos una serie de prácticas sociales que debieron estar vinculadas con la construcción de las diferentes fases arquitectónicas como también de los eventos de relleno del patio hundido. En síntesis, describimos y explicamos la planificación, construcción y uso del edificio principal de Cerro del Gentil durante la época Paracas Medio y Tardío. Además, describimos y explicamos el abandono del sitio por parte de las líderes de la sociedad Paracas en esta parte del valle. Finalmente, nos referiremos a la reutilización y modificación del edificio por los grupos sociales relacionados con la cerámica topará. Esta última ocupación humana es poco comprendida en la arqueología de la costa sur del Perú, pero tiene importantes implicancias para entender la prehistoria temprana del valle de Chincha y otros cercanos.

\section{Cerro del Gentil}

El sitio de Cerro del Gentil, también registrado por Dwight Wallace como PV.57-59, se encuentra en un área cercana a la entrada al valle medio de Chincha cuando este comienza a estrecharse debido a la presencia de las primeras estribaciones andinas (Fig. 1). El sitio fue construido en el extremo de una saliente ubicada en el borde de la pampa, que se eleva sobre el fondo del valle medio de Chincha y es contiguo a la quebrada Puerta Blanca (Fig. 2). Su localización en ese lugar tiene muchas ventajas, entre las que se pueden destacar el control visual del valle y de otros edificios paracas cercanos; la cercanía a una quebrada que trae agua estacionalmente; su ubicación intermedia entre la zona fértil del valle y la pampa eriaza; y, finalmente, debido a su altura, la posibilidad de realizar buenas observaciones del recorrido del sol en el firmamento, y su vinculación con accidentes geográficos y el mar.

Nuestras excavaciones se concentraron en el patio hundido central del edificio principal (Edificio 1), donde pudimos reconocer que este había sido remodelado en diferentes ocasiones (Fig. 3). Asimismo, se reconoció que alrededor del siglo III a.C. el edificio asociado a cerámica de estilo Paracas, después de su uso como espacio político-religioso, comenzó a ser enterrado con una serie de eventos de deposición de tierra y fragmentos de vasijas paracas, restos óseos, malacológicos y botánicos.

La segunda gran ocupación humana del edificio se vinculó con el estilo cerámico Topará. Esta última se registró principalmente en una plataforma construida al este del patio hundido excavado. Dicha plataforma presentó un volumen importante debido a las refacciones realizadas por el grupo social que usó la cerámica topará. En dicha plataforma, se identificó un par de recintos, 


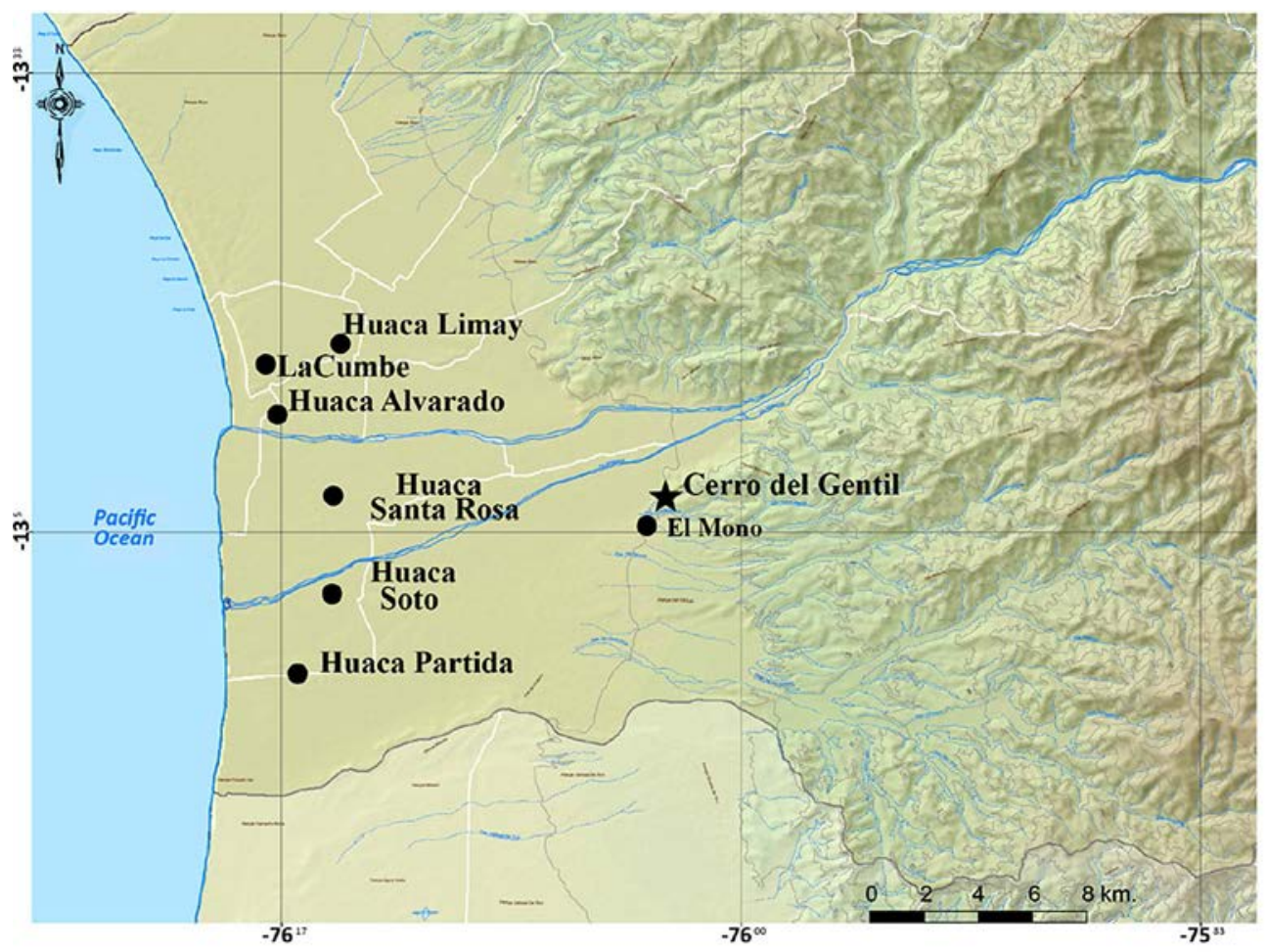

Figura 1. Mapa del valle de Chincha y ubicación de Cerro del Gentil (dibujo: Alexis Rodriguez).

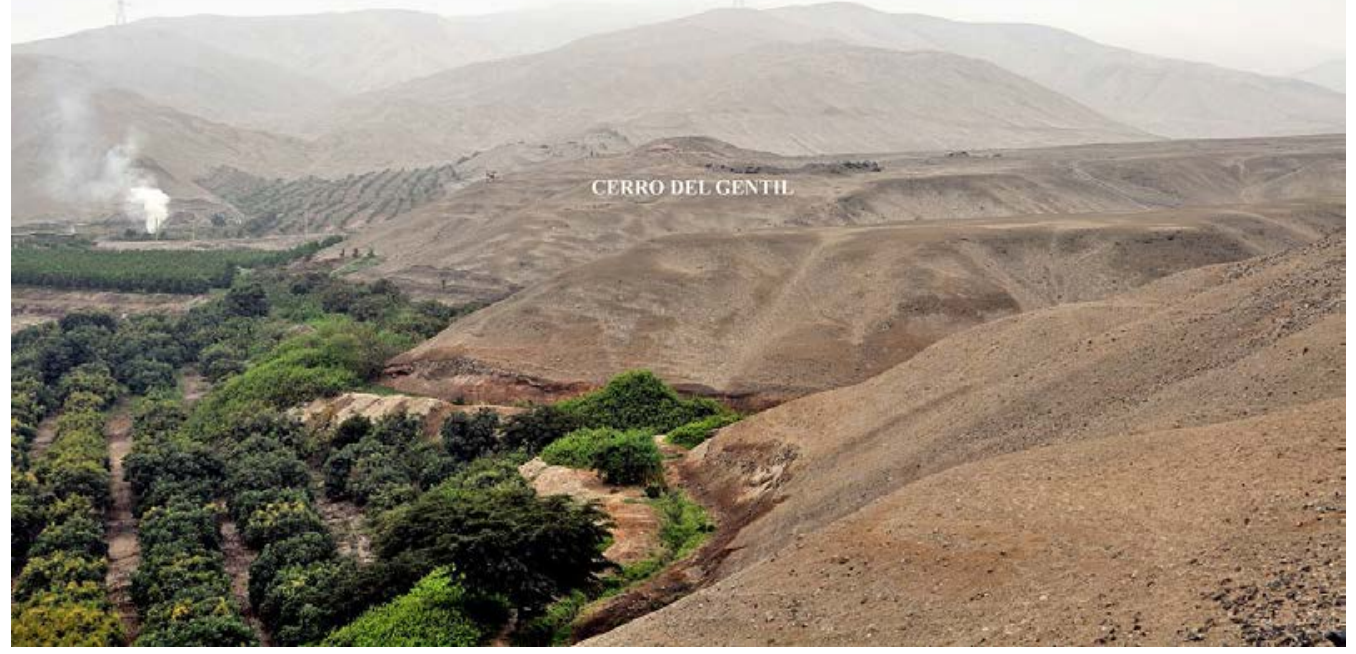

Figura 2. Vista de Cerro del Gentil desde el sur (foto: Henry Tantaleán). 


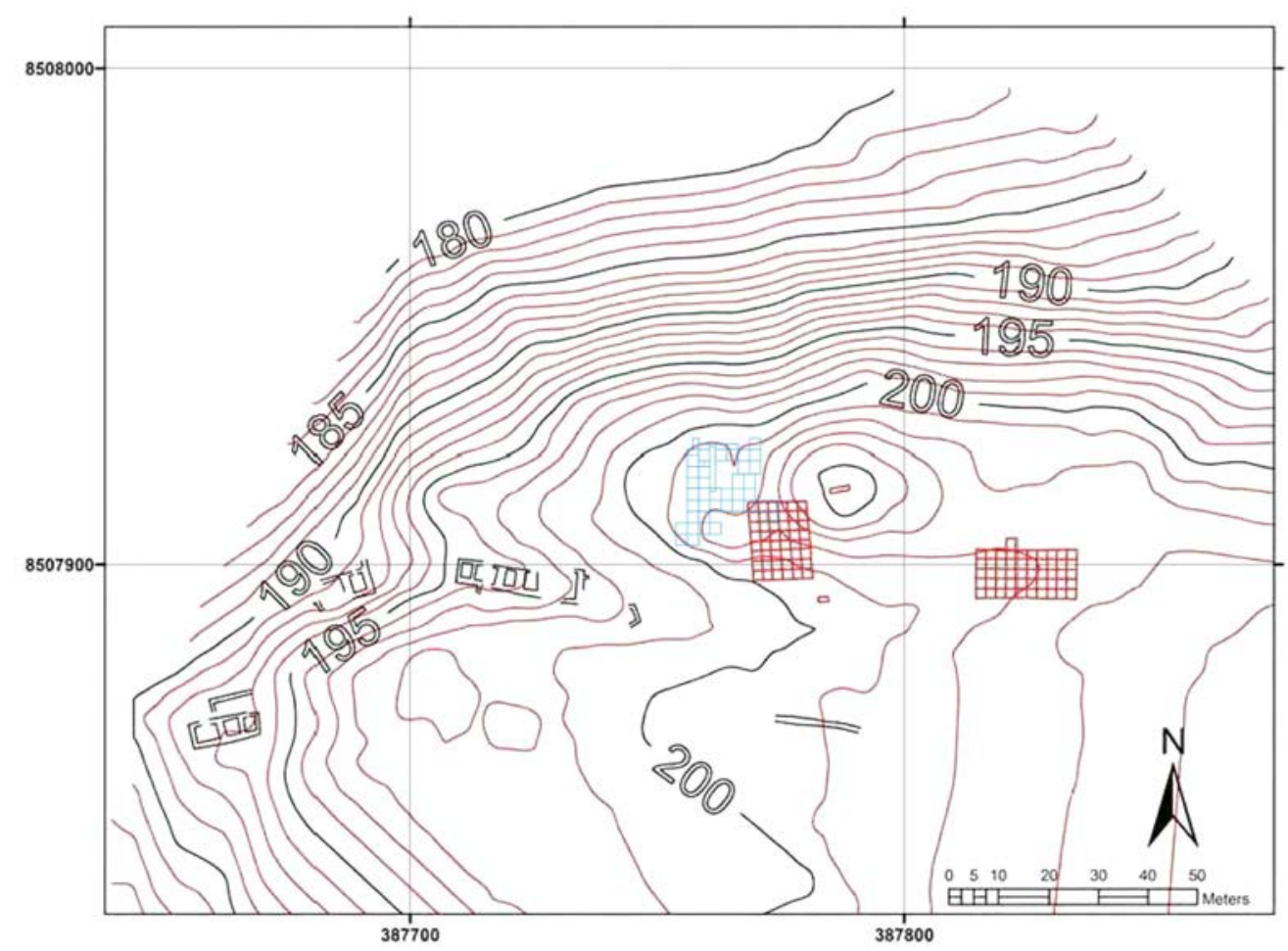

Figura 3. Plano de Cerro del Gentil con sectores excavados (plano: Alexis Rodríguez).

en uno de los cuales se encontró un fogón circular hecho a base de piedras no canteadas. Aunque es complicado identificar a ciencia cierta la función de estos espacios, podemos plantear que la complejidad de las prácticas fue comparativamente menor a las registradas en el momento de la ocupación paracas, aunque sugiere una función todavía supradoméstica para estos espacios.

El sitio también fue reocupado durante la época relacionada con el estilo cerámico Carmen en los siglos II y III de nuestra era (Pérez et al. 2015) y durante la época Chincha-Inca entre los siglos XIV y XVI, especialmente con estructuras funerarias. Sin embargo, en este artículo, solamente nos enfocaremos en las ocupaciones paracas $^{1}$ y topará. ${ }^{2}$

\section{La ocupación paracas}

Nuestras excavaciones en el sitio de Cerro del Gentil se realizaron en varios sectores, a partir de las cuales se identificó un área relacionada con un asentamiento vinculado al estilo Carmen del Período Intermedio Temprano (Sector B) (Pérez et al. 2015), y un sector con dos plataformas (Edificios 1 y 2) asociadas con arquitectura y cerámica Paracas. Sin embargo, nuestros trabajos se enfocaron en el Edificio 1, la plataforma más grande del sitio que fue denominado Sector A (Fig. 4). Durante nuestras excavaciones en el Edificio 1, definimos tres grandes fases constructivas relacionadas con Paracas: fase Amarilla, fase Gris y fase Marrón (Fig. 5, 6 y 7). Posteriormente a estas fases, se realizaron una serie de eventos de enterramiento ritual del edificio, especialmente evidenciados en el patio hundido de la parte central. 


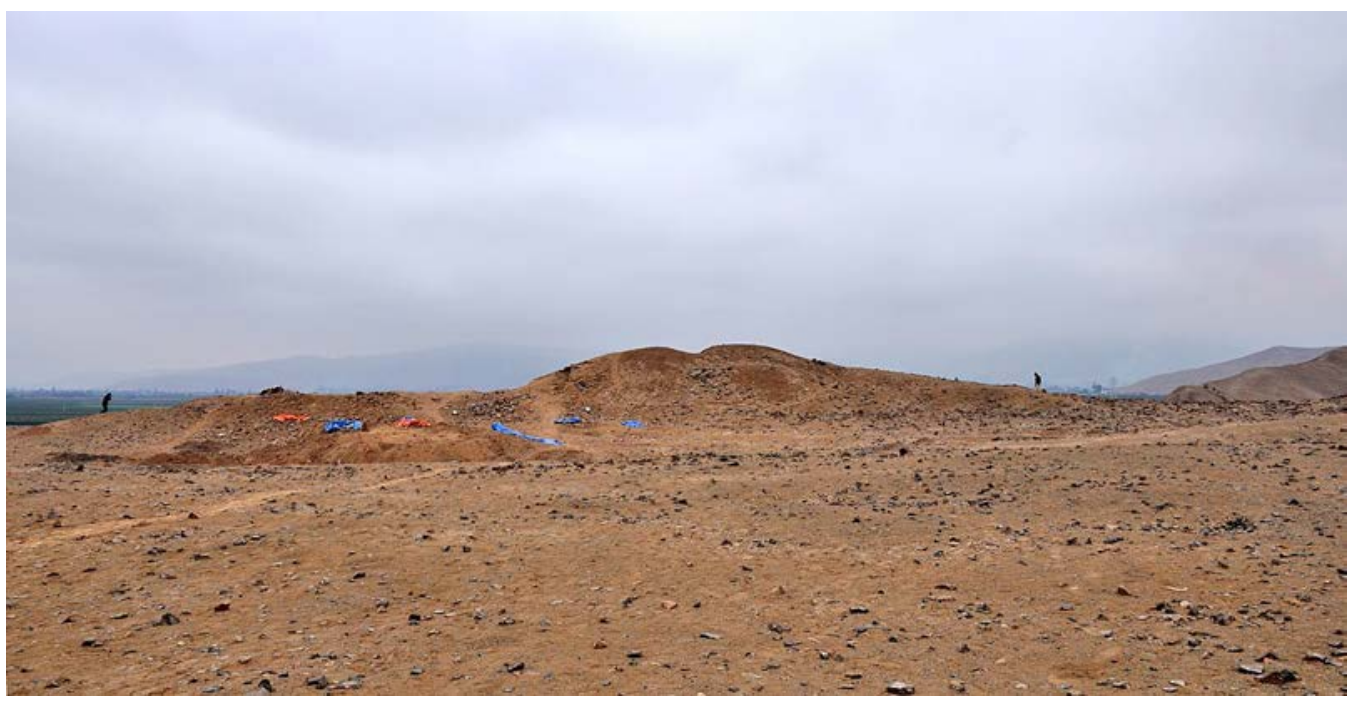

Figura 4. Vista desde el sur del Edificio 1 (foto: Henry Tantaleán).

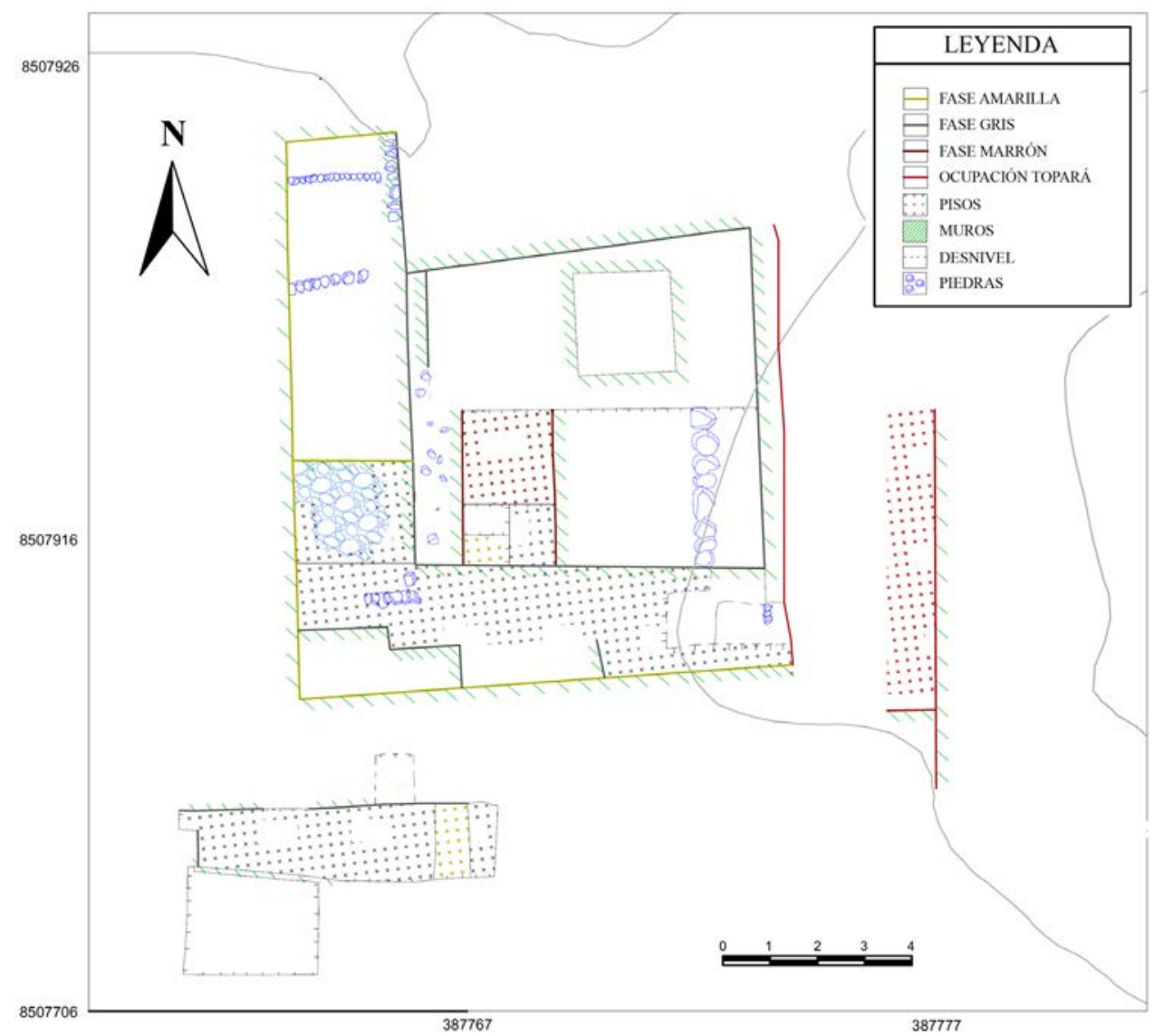

Figura 5. Plano con fases arquitectónicas (plano: Alexis Rodríguez). 


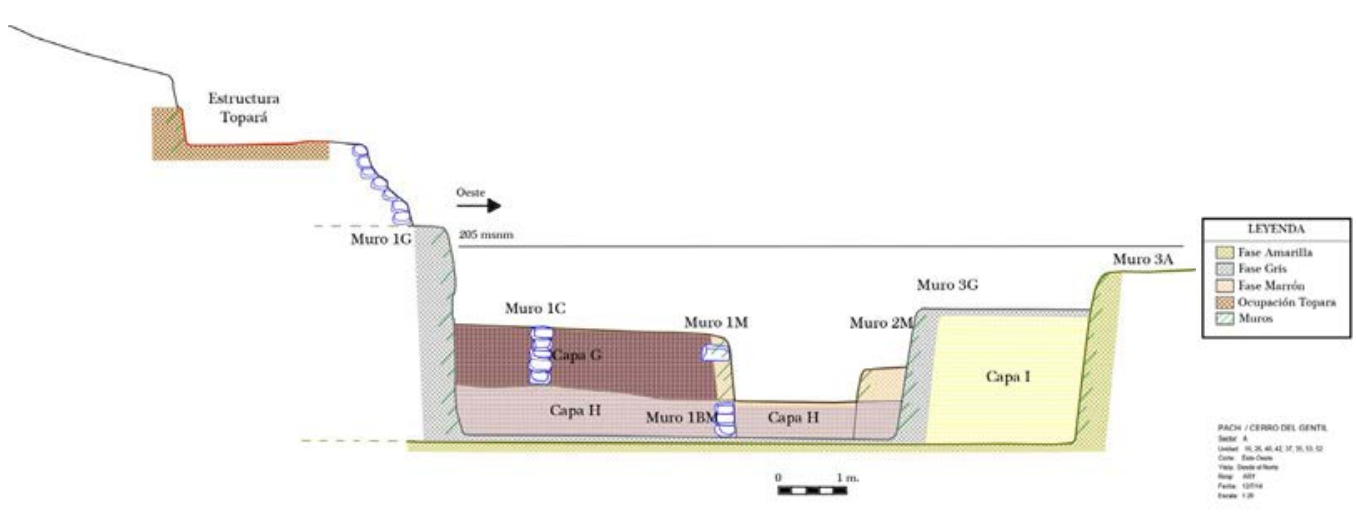

Figura 6. Corte este-oeste del patio hundido del Edificio 1 de Cerro del Gentil (dibujo: Alexis Rodriguez).

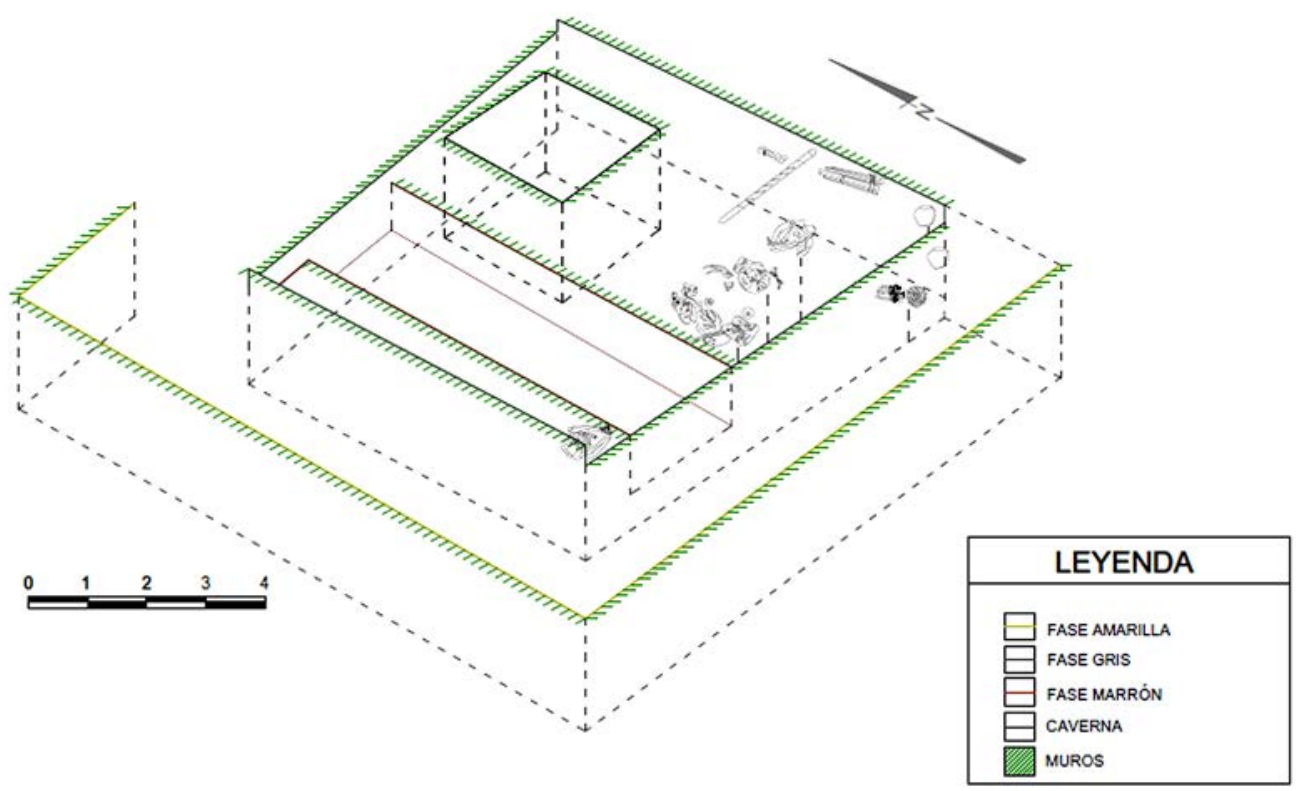

Figura 7. Reconstrucción de las fases en el patio hundido del Edificio 1 de Cerro del Gentil. También se observan las principales ofrendas y enterramientos incluidos en las capas de relleno del patio hundido (dibujo: Abel Fernández y Alexis Rodríguez).

\subsection{La fase Amarilla}

Durante la temporada de investigación 2013 y 2014, las excavaciones en el Edificio 1 lograron definir arqueológicamente un patio cuadrangular hundido, previamente planteado por José Canziani (1992: 105) (Fig. 8). La planificación del edificio tomó en cuenta una configuración que estuvo relacionada con la orientación principal del edificio en un eje oeste-este, configuración que también se reitera en los muros del patio hundido y otras estructuras del edificio.

De acuerdo con nuestras excavaciones, para empezar a construir el patio hundido, primero, se colocó un piso grueso de fundación preparado con arcilla. Dicho piso fue plenamente identificado hacia el noroeste de la segunda plataforma; sin embargo, no se encontró hacia el sureste de la plataforma. 


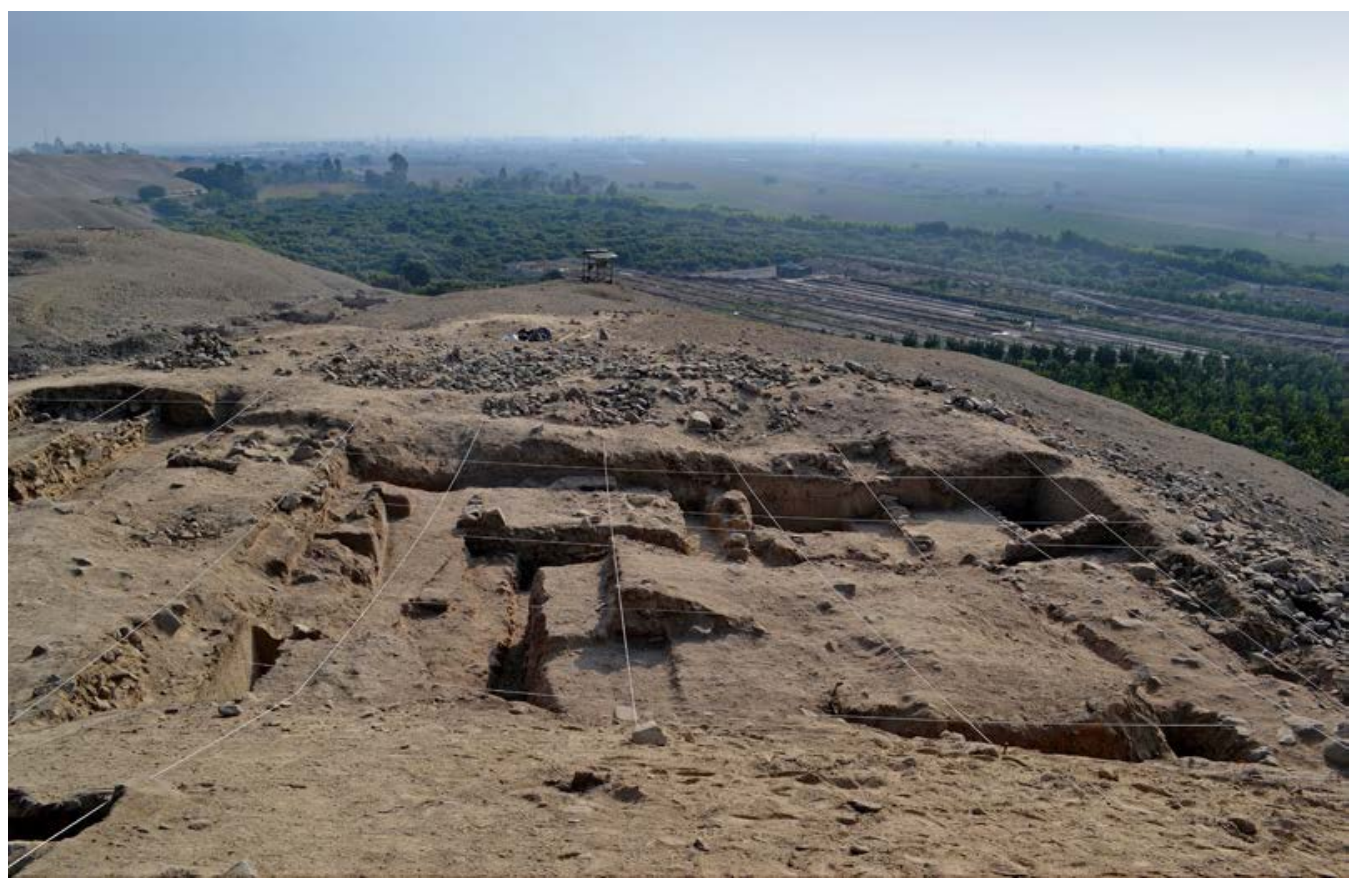

Figura 8. Vista desde el este del patio de la fase Amarilla (foto: Henry Tantaleán).

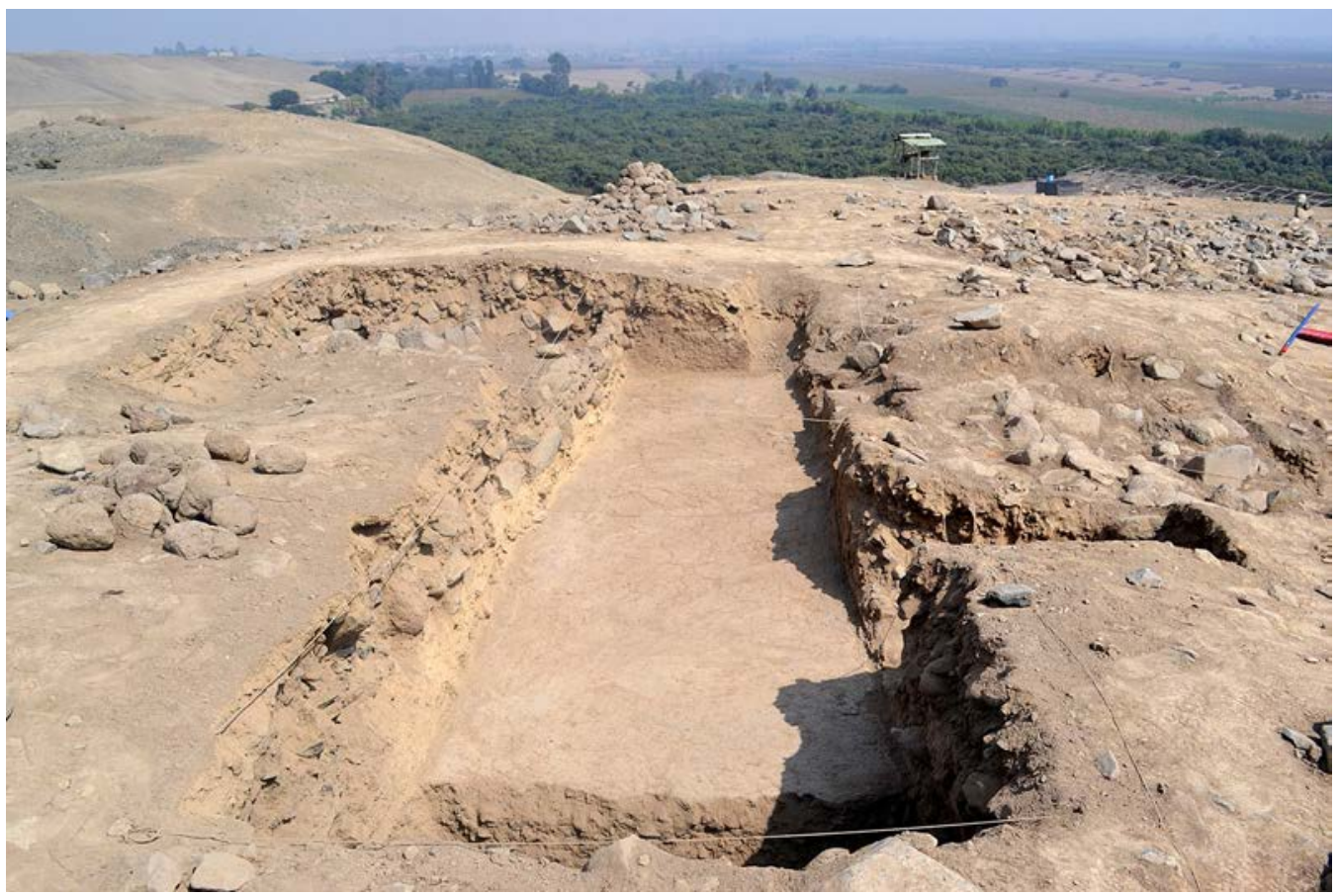

Figura 9. Vista desde el este del corredor (foto: Henry Tantaleán). 
Esto nos hace pensar que el piso fue construido con el fin de nivelar el terreno antes de proceder a construir los muros del patio cuadrangular hundido. Sobre ese piso, se depositó un relleno de tierra con piedras pequeñas angulosas y con muy poco material arqueológico, con excepción de algunos restos botánicos.

Sobre esa primera capa, se construyó un nuevo piso de arcilla, el cual se encontraba asociado directamente a los muros que conforman la primera fase constructiva del patio hundido. Denominamos a esta como la fase Amarilla, la cual estuvo vinculada directamente con la construcción del primer patio hundido y que se correspondería a los primeros muros evidenciados al sur en las excavaciones de la temporada 2012 (Tantaleán et al. 2013: fig. 7). El primer patio hundido fue acompañado por otras estructuras como un corredor evidenciado al sur (Fig. 9). Hacia el norte del patio hundido, la edificación estuvo tan destruida por entierros intrusivos y saqueo, que solo se reconoció el paramento interior del muro norte de dicho patio. Hacia el este, la superposición de la plataforma topará no permitió reconocer hasta dónde se extendía el patio hundido de la fase Amarilla u otras estructuras arquitectónicas subyacentes. De acuerdo con las observaciones de otros edificios contemporáneos del valle, se puede plantear que existió un segundo patio hundido debajo de la plataforma topará. De hecho, nuestras excavaciones limitadas en el extremo este del edificio expusieron un muro que sería parte de dicho patio. Hoyos de postes de madera sobre dicho muro evidencian que, como en Huaca Soto, este patio hundido habría estado techado (Stanish y Tantaleán 2015; Stanish y Pérez 2016).

El patio hundido de la fase Amarilla tiene 12 metros por 12 metros y unos 2,50 metros de profundidad, medidos desde las cabeceras de los muros excavados hasta el piso del fondo. Los muros fueron construidos con adobes cónicos (también reconocidos por otros autores como en forma de cuña) (Wallace 1971; Lumbreras 2008; Canziani 2009) y el paramento interno fue cubierto con finos enlucidos de barro de color amarillento. Su buena conservación se debe a que este patio fue cubierto para construir sobre ellos los muros del patio hundido de la fase Gris. El relleno, también de tierra de color amarillento, contenía poca cantidad de materiales arqueológicos y algunas ofrendas.

\subsubsection{Prácticas sociales durante la fase Amarilla}

3.1.1.1. Fundación de Cerro del Gentil: El edificio fue construido sobre la base natural del «espolón» al final de la pampa que se eleva sobre el valle. La elección de este lugar debió tener como objetivo utilizar la elevación y su ubicación al borde de la pampa para visualizar una mayor parte del paisaje circundante, especialmente del fondo del valle irrigado.

Para la construcción del Edificio 1, el área parece haber sido nivelada, lo cual se evidencia en las excavaciones en el fondo del patio hundido. Sobre esta superficie nivelada, se hallaron restos de hojas de maíz que podrían haber formado parte de un ritual de fundación del edificio. Estas hojas de maíz se dispusieron agrupadas sobre el relleno utilizado para la nivelación del terreno. Posteriormente, se construyó el primer piso de barro del edificio.

3.1.1.2. Establecimiento de la configuración original: El edificio principal fue diseñado originalmente como una plataforma rectangular orientada en su mayor eje en dirección oeste-este. En las excavaciones de 2012, se evidenció que las partes laterales, al menos en el lado sur, fueron niveladas con la acumulación de bloques de piedra cortada. Sobre esta capa, se superpusieron muros hechos con adobes cónicos. En la parte sur, se evidenció que estos fueron retenidos por muros de piedras canteadas, sobre las cuales se adosaban adobes cónicos con la base hacia el exterior (Tantaleán et al. 2013: fig. 7). Hacia el interior de estos muros de retención de piedra, se colocaron adobes cónicos con la base hacia abajo, lo cual creaba el volumen de la plataforma.

3.1.1.3. Espacio y uso del patio hundido de la fase Amarilla: Nuestras investigaciones confirmaron que el acceso principal al edificio no estuvo en la parte central del extremo este. Así, a menos que el acceso se haya encontrado en los lados norte o sur, el mejor lugar para ingresar al edificio debió 


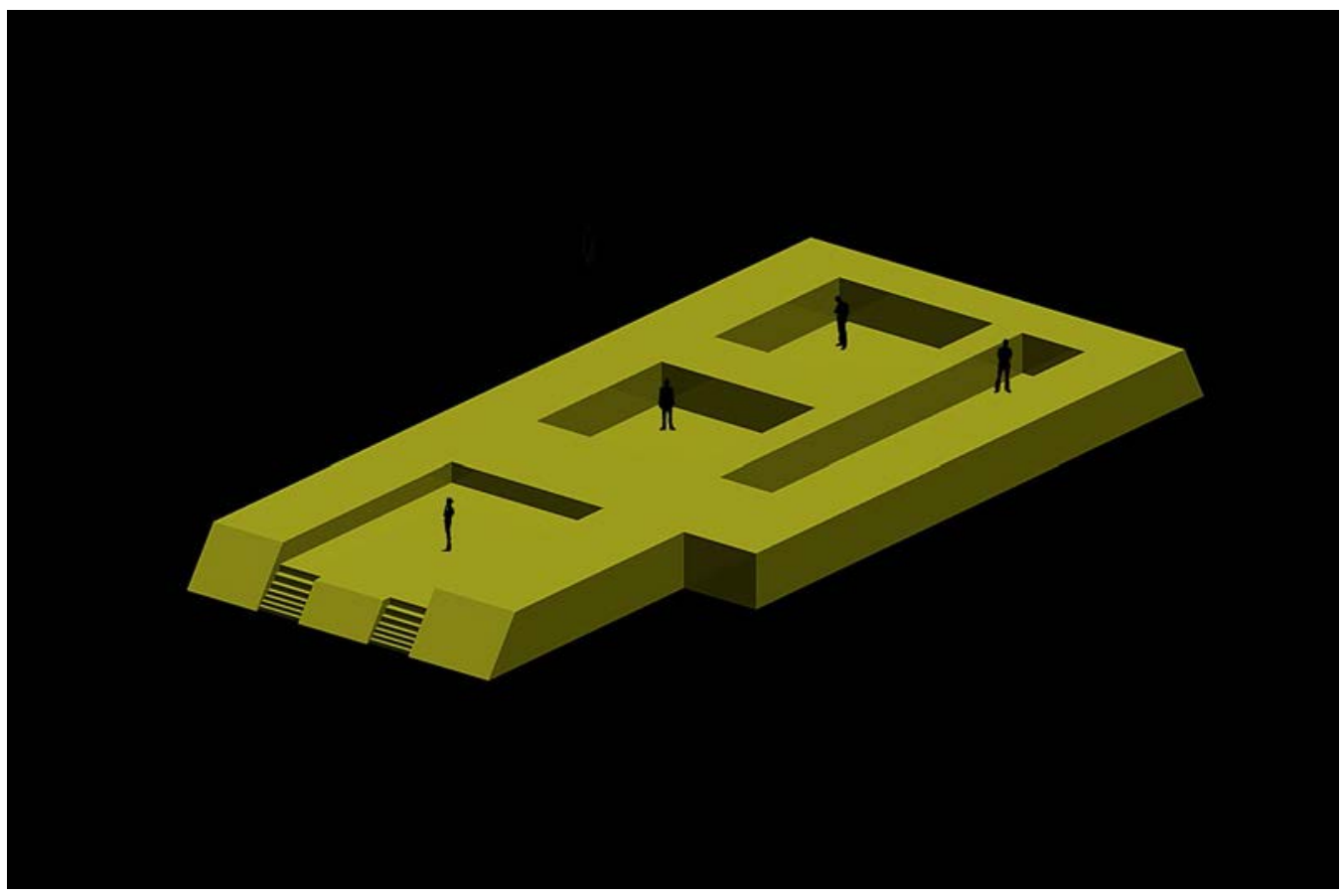

Figura 10. Reconstrucción artistica del Edificio 1 durante la fase Amarilla (dibujo: Henry Tantaleán y Alexis Rodriguez).

haber sido el extremo oeste. Sin embargo, en la parte central del lado oeste, nuestras excavaciones registraron que los constructores habían elevado esta parte con muros de piedra semicanteada recubiertos con barro. Nuestra propuesta es que dos escalinatas incrustadas en el talud de la plataforma oeste fueron los accesos al atrio principal del edificio (Fig. 10). Este atrio sería similar a los propuestos por Canziani $(1992,2009)$ para otros edificios paracas de la parte baja del valle. Nuestras excavaciones evidenciaron que este atrio tuvo un piso de barro preparado. Atravesando el atrio, se llegaba a un segundo nivel donde tenemos el conjunto del patio hundido. Dicho patio hundido estuvo circundado por una serie de recintos, de los cuales se han podido definir solamente los de la parte oeste. Se trataba de estructuras construidas con piedras canteadas y revestidas de barro. Algunos de los muros de esos recintos debieron estar pintados de colores, puesto que hemos encontrado fragmentos de enlucidos pintados dentro de los escombros arrojados al interior del patio hundido. Los diseños de dichas paredes eran geométricos, y formaban patrones de cruces en colores negro, rojo y blanco (Fig. 11).

Pese a nuestros esfuerzos, el acceso al mismo patio hundido tampoco se pudo definir. No obstante, dada la escala pequeńa del patio y el sistema de construcción con muros adosados a las bases del patio, es plausible que estos hayan sido usados como peldaños. Otra posibilidad es que se haya utilizado alguna especie de escalera móvil de material botánico. En el caso de Huaca Soto, estos accesos se encuentran insertos en los mismos muros del patio (Stanish y Pérez 2016).

El espacio principal del edificio sería el patio hundido central; de darse reuniones en su interior, este habría podido reunir a un grupo pequeño de no más de 50 personas en posición de pie. Si las personas se acomodaron solamente sentados sobre los muros de apoyo — como los evidenciados en el norte del patio hundido, que podrían haber sido utilizados como banquetas — podríamos obtener una cantidad menor de participantes. Una hipótesis es que una de las principales actividades sociales allí realizadas era la observación del sol y la consecuente medición del tiempo (Tantaleán 2016). 


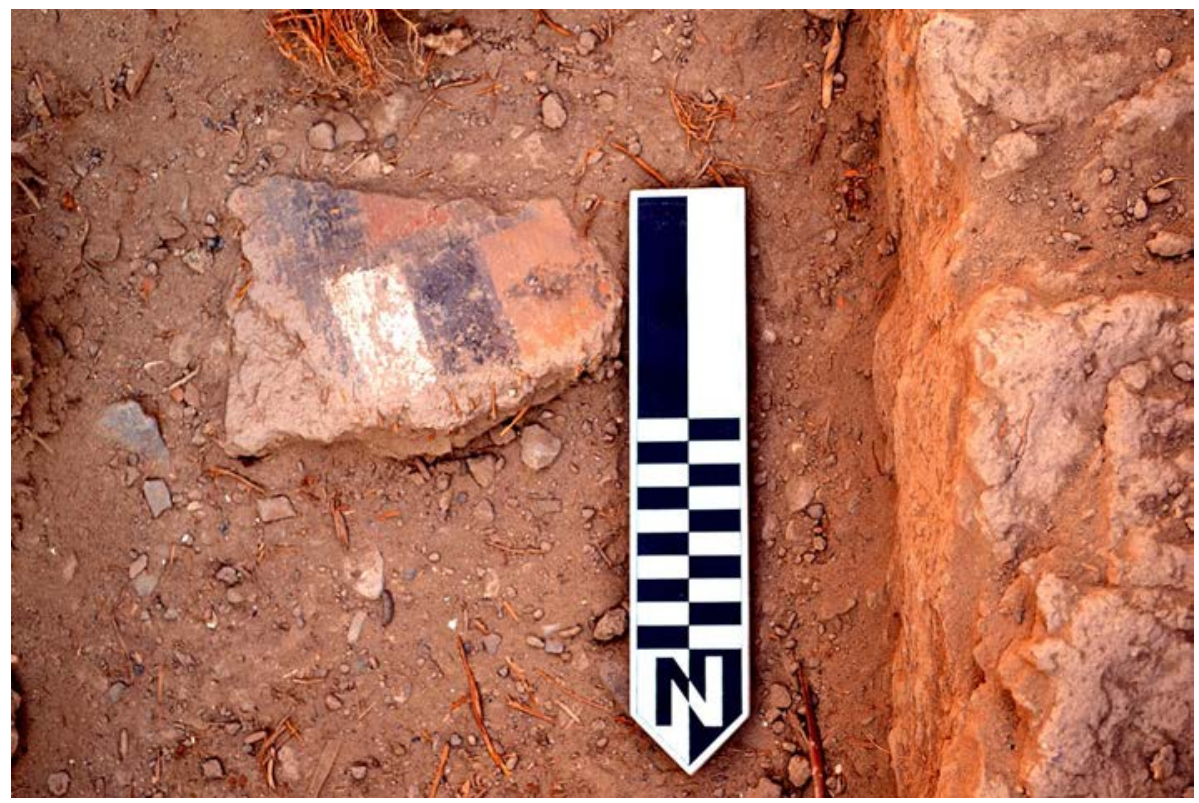

Figura 11. Fragmento de enlucido con diseños pintados (foto: Henry Tantaleán).

Dichas actividades u otras estarían acompañadas de ritos con consumo de bebidas y comida al interior del patio (Tantaleán et al. 2016).

La altura de los muros impediría que las actividades realizadas en su interior sean observadas desde el exterior del edificio. Estas actividades solo podrían ser observadas desde los recintos o espacios abiertos circundantes al patio hundido. Una configuración arquitectónica similar a este complejo es el de los templos de Pukara en Puno, que también incluyen un patio hundido y una estructura que circunda al patio (Mujica 1991). Resulta interesante que, de la misma manera que en Pukara, los muros del patio de la fase Amarilla estaban orientados hacia los puntos cardinales.

\subsection{La fase Gris}

Luego de un tiempo de uso, se realizó una gran modificación del espacio arquitectónico, definido como una nueva fase constructiva. El nuevo patio de la fase Gris fue construido dentro del espacio original del primer patio hundido (fase Amarilla) y, de esta manera, quedó inserto dentro de aquel (Fig. 12). La construcción de esta nueva fase comenzó con la superposición de un nuevo piso sobre el fondo del patio de la fase anterior. Sobre este piso, se levantaron cuatro nuevos muros de piedra y barro que completaron el patio de esta nueva fase. El relleno que cubrió los muros del patio de la fase Amarilla quedó depositado entre su paramento exterior y el paramento interior de los muros de la fase Gris.

El patio cuadrangular hundido de la fase Gris midió siete metros por siete metros, aproximadamente, y una altura de aproximadamente 2,40 metros de profundidad. Salvo el muro norte que está desviado algunos grados hacia el sureste, todos los muros del patio estuvieron orientados hacia los puntos cardinales. Este relleno también les otorgó estabilidad y solidez a los muros del nuevo patio. Dicho relleno estaba compuesto de tierra limosa de color amarillento libre de piedras grandes y con muy poco material cultural asociado. Dentro de este relleno, se encontraron algunos rasgos y ofrendas, especialmente cerca de la esquina sureste. Es importante resaltar que, luego de la deposición del relleno en la parte sur y oeste, se hizo un piso de barro a la altura de la cabecera del muro sur y oeste del patio en esta nueva fase. Este piso se adosó además a la parte superior de los muros sur y 


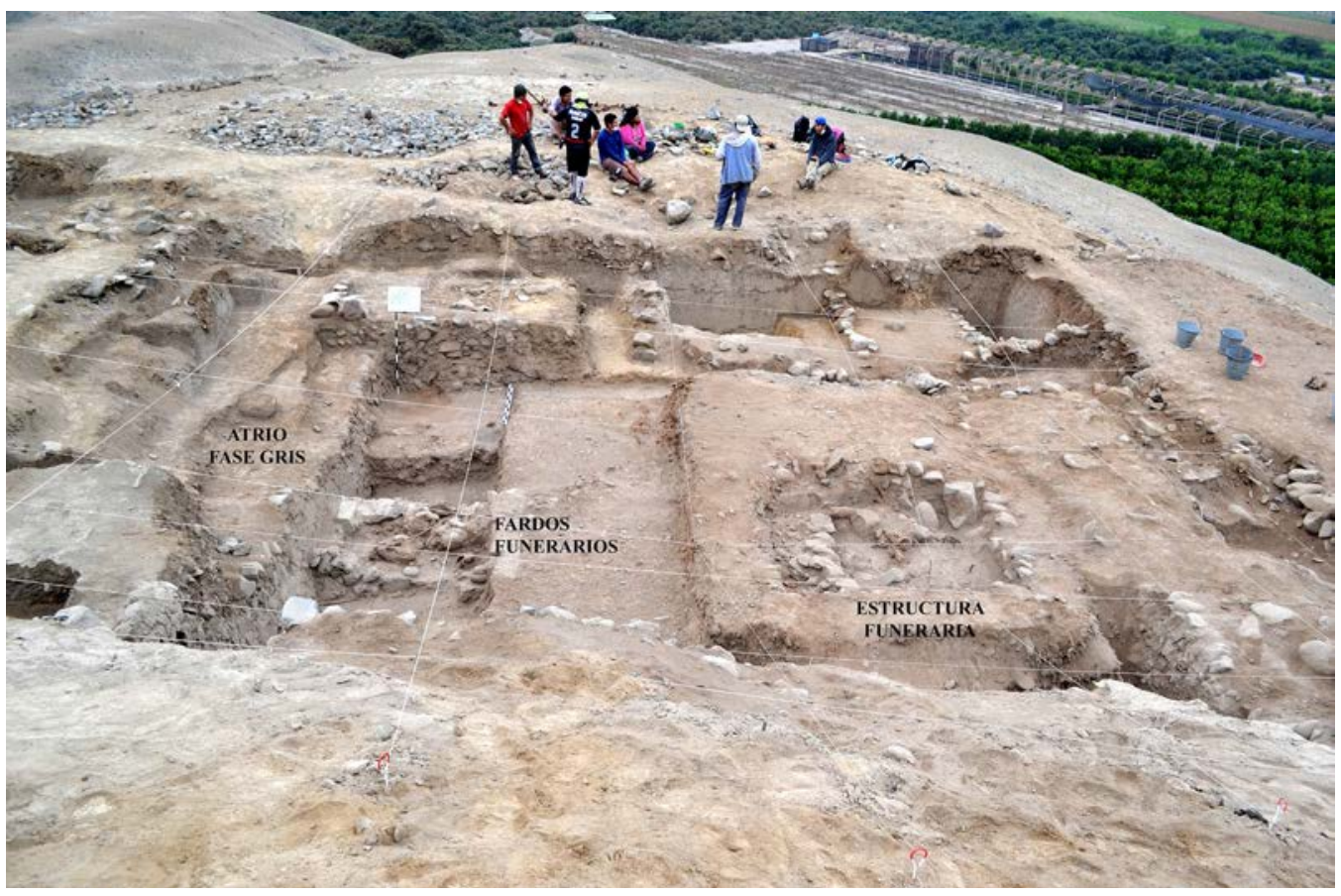

Figura 12. Vista desde el este del patio de la fase Gris (foto: Henry Tantaleán).

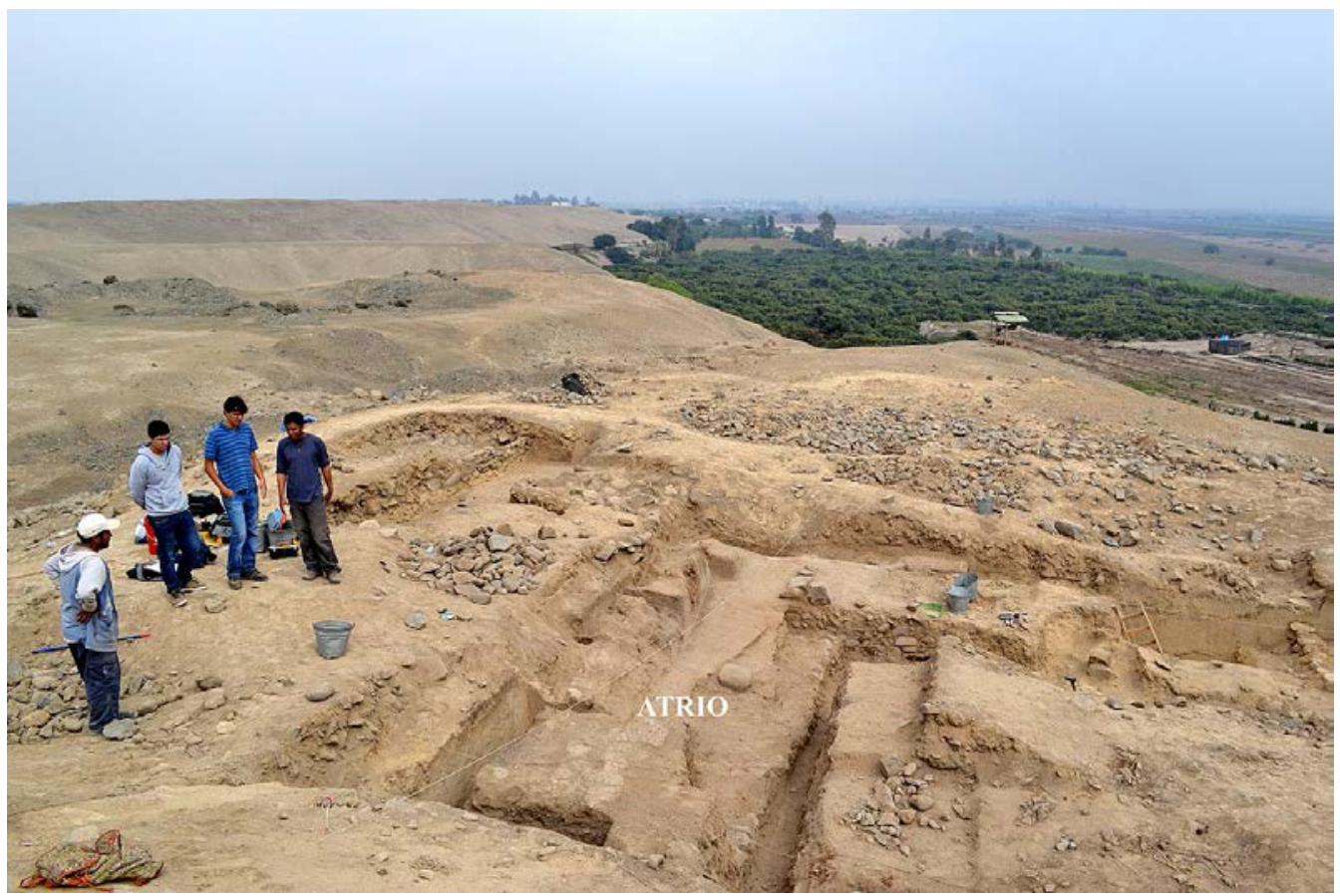

Figura 13. Vista desde el este del atrio de la fase Gris (foto: Henry Tantaleán). 
oeste del patio hundido en la fase Amarilla. Todo ello configuró un espacio que estaría funcionando conjuntamente con el patio cuadrangular hundido de la fase Gris. A este espacio lo hemos denominado "Atrio del patio hundido de la fase Gris» (Fig. 13). Dada la configuración del patio hundido de la fase Amarilla, debemos pensar que también se contó con un atrio similar. Un corredor hacia el sur del patio hundido se correspondería con este atrio y patio hundido. Excavaciones de profundización debajo del piso del corredor de la fase Gris evidenciaron que, luego de un relleno similar al que cubrió los muros del patio de la fase Amarilla, también este corredor tuvo una mayor profundidad, y que debió haber estado asociado con el atrio y el patio de la fase Amarilla.

\subsubsection{Prácticas sociales durante la fase Gris}

3.2.1.1. Entierro de los muros de la fase Amarilla y construcción de los muros del patio de la fase Gris: El entierro del patio hundido de la fase Amarilla fue un evento social importante que resultó en la reducción de las dimensiones de dicho espacio. Así también, terminó afectando el desarrollo de las actividades realizadas en general en este edificio. Fue un evento que, además, involucró un importante trabajo de personas, que acarreó material limpio para cubrir el patio antiguo, el atrio y el corredor sur de la fase Amarilla. Asimismo, se debió planificar la nueva configuración de los muros, la obtención de materiales y el trabajo involucrado para construir el nuevo patio. Sin embargo, se puede notar que los materiales utilizados en los nuevos muros del patio de la fase Gris fueron heterogéneos y de baja calidad comparados con los de la fase Amarilla. Por ejemplo, se utilizó una gran cantidad de bloques de piedra y los enlucidos de las paredes fueron menos finos que los de la fase Amarilla. Además, la desviación del muro norte de la fase Gris plantea que, si no fue parte de la corrección de la orientación de este muro por razones aún desconocidas, es posible que la desviación se deba a problemas constructivos.

3.2.1.2. Actividades en el patio de la fase Gris: Durante la fase Gris, se seguirían realizando las mismas actividades realizadas en el patio de la fase Amarilla, debido a que la disposición de los ejes de los muros principales y la configuración del espacio central siguió siendo la misma. En suma, lo que habría pasado es que se redujo el tamaño del patio hundido y de su atrio. Otra vez, no encontramos evidencias de accesos formales, aunque se podrían haber usado también los muros de apoyo que corren pegados a las bases del patio hundido. El atrio del patio hundido también incluyó una serie de escalinatas de, al menos, dos escalones. Lamentablemente, dicha escalinata se encontró bastante destruida por la erosión, los entierros intrusivos y por un evento que fracturó el piso del atrio, quizá un terremoto. Asimismo, al oeste del borde del patio hundido, se evidenció la base de muros de recintos y que habrían sido espacios relacionados con las actividades llevadas a cabo en el patio. El espacio, con lo reducido que fue, debió haber albergado un menor número de personas, quizás unas 20 como máximo. Las actividades de observaciones astronómica dentro y cerca al patio hundido y el consumo de bebidas y alimentos al interior y en las áreas externas debieron ser las actividades más importantes durante el funcionamiento del patio durante la fase Gris (Tantaleán 2016, Tantaleán et al. 2016). En general, la reducción y la calidad de los muros de esta fase indican que la reducción y mantenimiento del espacio estuvo influenciado por algún problema social especialmente de los grupos que controlaban este sitio.

\subsection{La fase Marrón}

Luego de un tiempo de uso del patio hundido de la fase Gris, el espacio nuevamente fue modificado, a partir de lo cual se definió una nueva fase constructiva, denominada «fase Marrón» (Fig. 14). Para la construcción de las estructuras arquitectónicas concernientes a esta nueva fase, primero, se depositó una capa de relleno de tierra limosa (asociada con material cultural Paracas) sobre el piso del patio hundido de la fase Gris. Luego de rellenar 0,50 metros sobre ese piso, se levantó una plataforma delimitada por muros de piedra con relleno de tierra en el sector este del patio. Dicha plataforma tiene una extensión de siete metros en eje norte-sur por cuatro metros en eje oeste-este, 


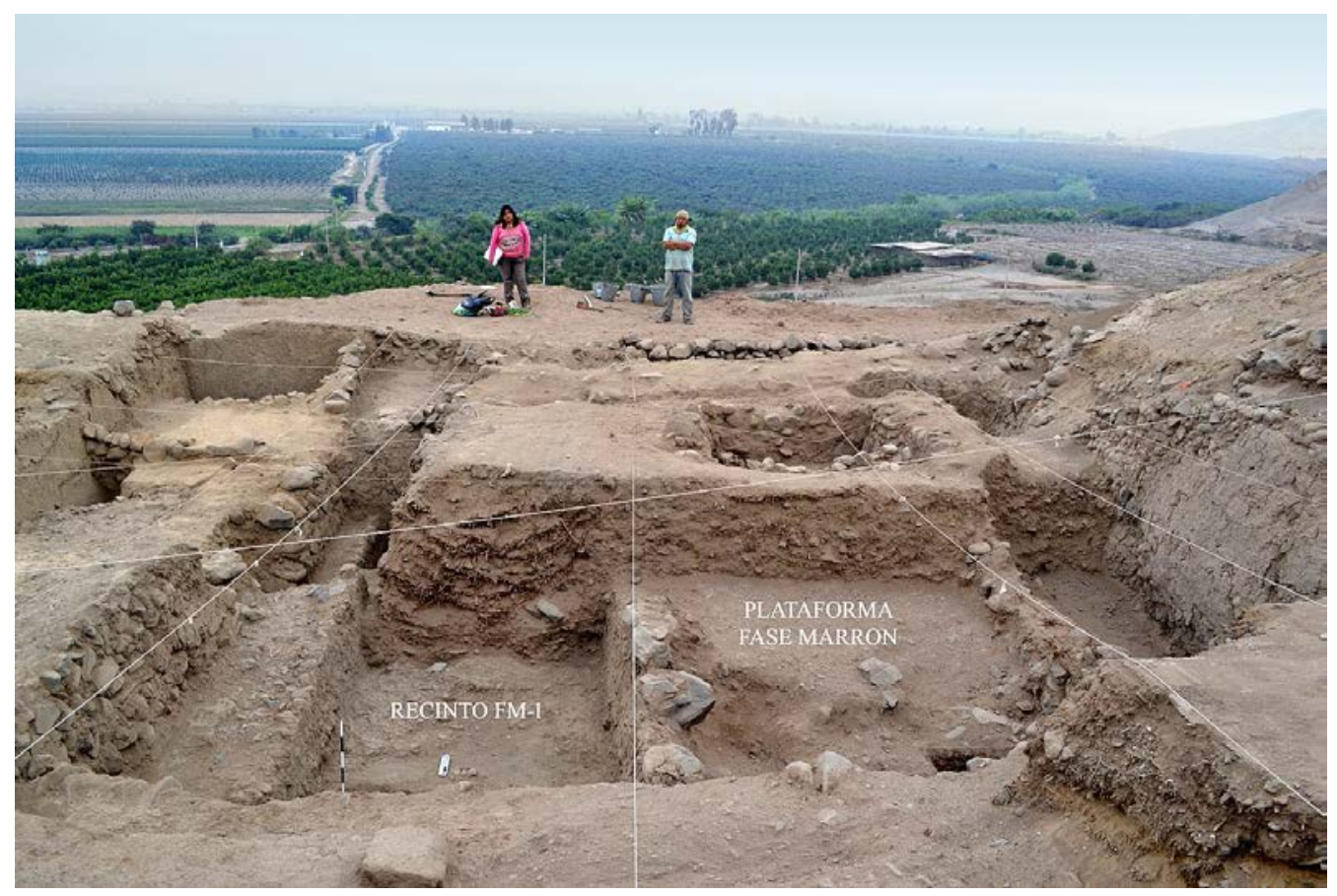

Figura 14. Vista desde el sur de los muros de la fase Marrón (foto: Henry Tantaleán).

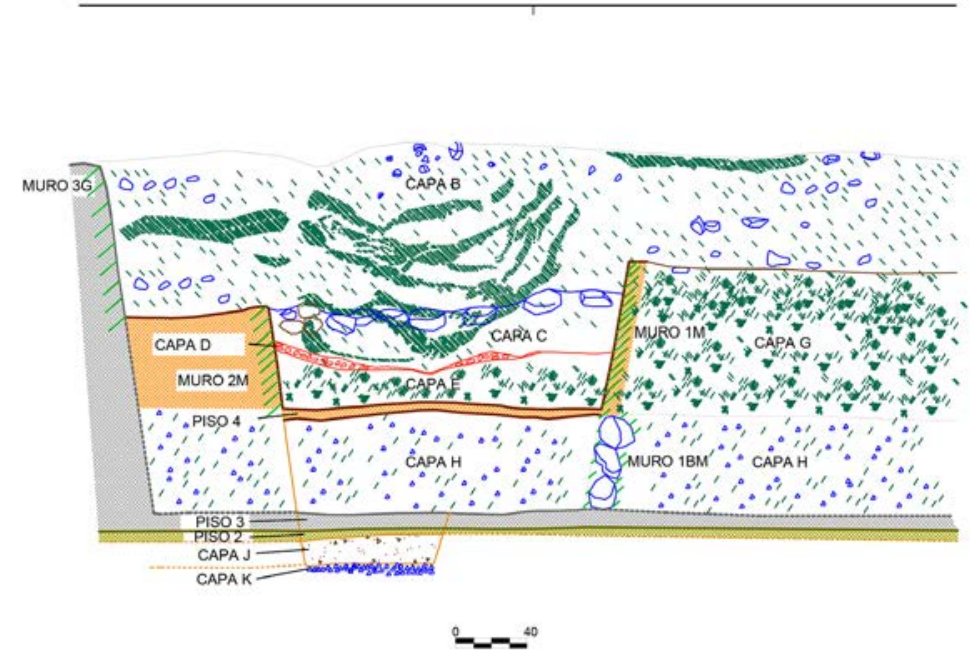

\begin{tabular}{|l|}
\hline LEYENDA \\
\hline Fase Marrón \\
$\square$ Fase Gris \\
$\square$ Fase Amararilla \\
Muros \\
Tierra limpia \\
Material botánico \\
Coprolitos de cury \\
Cierra limosa de maiz \\
\hline Piedras
\end{tabular}

PACH / CERRO DEL GENTIL

Sector: A

Perfil: Norte

Unid: $\quad 40,42,37$

Resp: AFPIARY

Fecha: $13 / 7 / 14$

Escala: $1: 20$

Figura 15. Perfil norte de las unidades de excavación 40, 42 y 37. Se observan estructuras arquitectónicas, rasgos y capas depositadas durante el proceso de enterramiento del patio hundido (dibujo: Henry Tantaleán y Alexis Rodríguez). 
con un espesor promedio de 0,90 metros. La altura de dicha plataforma llegó a la altura de las cabeceras de los muros de la fase Gris, y se apoyó en los muros norte, sur y este de la misma fase. A lo largo del muro oeste del patio hundido, se construyó un nuevo espacio rectangular de dos metros en el eje norte-sur por siete metros en el eje este-oeste y 0,90 metros de profundidad. Hemos denominado a este espacio como el Recinto FM-1.

El Recinto FM-1 está delimitado por el muro $1 \mathrm{M}$ de la plataforma al este del patio y el muro $2 \mathrm{M}$ que se adosa al muro oeste (3M) del patio de la fase Gris (Fig. 15). Los extremos norte y sur son las paredes del antiguo patio de la fase Gris. Finalmente, tiene un piso construido sobre la capa de relleno que cubrió el piso de la fase Gris. De esta manera, tanto la plataforma como el Recinto FM-1 para la fase Marrón y el atrio de la fase Gris (el cual creemos no se refaccionó) estarían configurando un nuevo espacio de uso social, el cual se caracteriza por una distorsión del planeamiento original del patio cuadrangular hundido de la fase Gris.

\subsubsection{Prácticas sociales durante la fase Marrón}

3.3.1.1. Modificación del patio hundido: La reducción del espacio original vinculado con la tradición de patios hundidos se hizo utilizando la misma técnica de construcción paracas. Por tanto, debemos inferir que fueron los encargados de la construcción del edificio original quienes plantearon y ejecutaron la construcción de la plataforma al este y el recinto FM-1. El único espacio que pudo haber sido utilizado en este momento debió ser el espacio libre del recinto FM-1, una suerte de corredor. Tuvo un piso preparado con barro que se asociaba con los enlucidos de los muros $1 \mathrm{M}, 2 \mathrm{M}$, y de los muros norte y sur del patio de la fase Gris. Hipotetizamos que este espacio rectangular fue dejado libre para realizar actividades vinculadas con la clausura de las actividades rituales del patio hundido. Los fechados radiocarbónicos indican que esta fase fue construida en un lapso de tiempo corto entre la construcción de la fase Gris y la colocación de los rellenos que sellaron el antiguo patio hundido (Tantaleán et al. 2016: fig. 8 y tabla 1).

3.3.1.2. Rellenos sobre la fase Marrón y el antiguo patio hundido: Sobre el Recinto FM-1, la plataforma este y el atrio, hasta alcanzar la altura de los muros más altos del patio hundido, se colocaron una serie de capas de relleno. Hemos identificado al menos ocho grandes deposiciones de relleno o eventos (Fig. 15). Algunos de ellos difieren en la composición y contenido del depósito. En general, se evidencia que son restos de actividades llevadas a cabo en otro lugar, mezclados con materiales botánicos, tierra y escombros. La primera capa importante en ser depositada fue la capa denominada «E». En esta capa, se encontró gran cantidad de fragmentos de cerámica paracas (Fig. 16 y 17). Otra importante capa depositada a continuación fue la única que parece haber sido el resultado de una actividad in situ relacionada con el uso del Recinto FM-1: un posible corral de cuyes. Este tipo de actividad se infirió por la presencia de gran cantidad de coprolitos de esta especie. Las demás capas estuvieron compuestas de tierra, materiales botánicos, bloques de piedra y restos de enlucidos seguramente procedentes de los recintos al oeste del patio hundido. Entre esos materiales depositados, se hallaron ofrendas depositadas ex profeso. Una gran cantidad de tallos y hojas de maíz fueron encontradas en estas capas.

Por su parte, las denominadas Capas B y C contuvieron una serie ofrendas y entierros humanos (Fig. 7). De especial relevancia, fueron la Ofrenda 97, una olla sin cuello que contenía vasijas cerámicas, mates y cestas paracas (ver Tantaleán et al. 2013); un conjunto de seis fardos funerarios (Fig. 18); el enterramiento de un individuo sobre el muro oeste del Recinto FM-1 de la fase Marrón en la esquina suroeste del antiguo patio hundido (Fig. 19); y el enterramiento de un niño (Tantaleán et al. 2013: fig. 13). Otras ofrendas incluyeron vasijas enteras, paquetes textiles, artefactos de madera, artefactos hechos de hueso animal y fragmentos de vasijas rotas in situ.

Adicionalmente, se excavó una estructura funeraria incluida dentro de este relleno (Fig. 20). Esta tenía paredes de piedra e intruyó el relleno de capas y la plataforma de la fase Marrón en la zona noreste del patio, y llegó casi hasta el nivel del piso del patio de la fase Gris. Esta fue una 


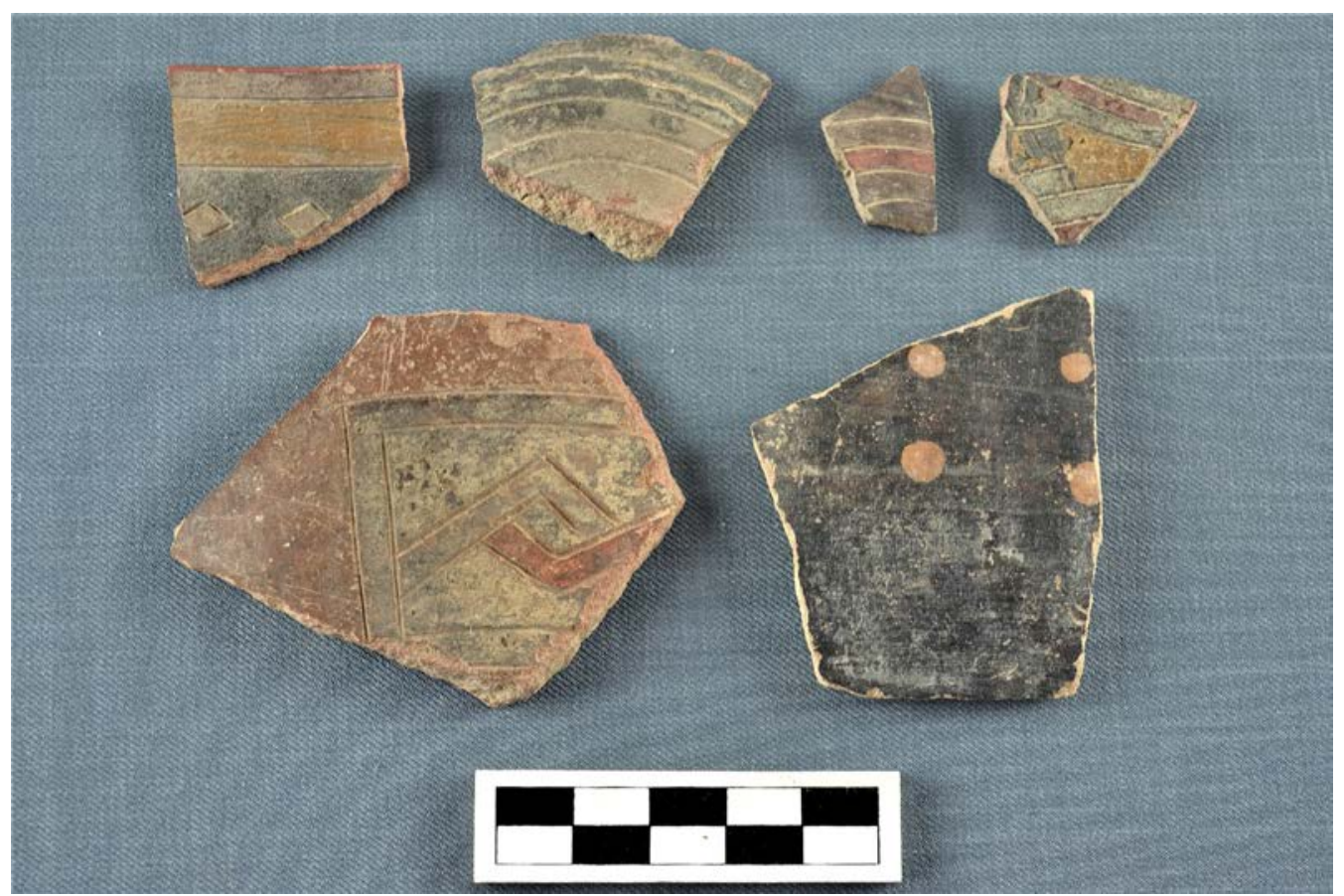

Figura 16. Fragmentos de cerámica Paracas Cavernas encontrados en las excavaciones (foto: Henry Tantaleán).

a)

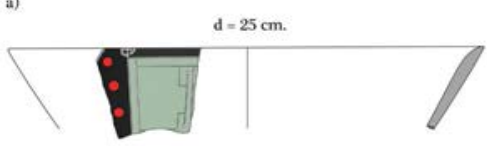

b)

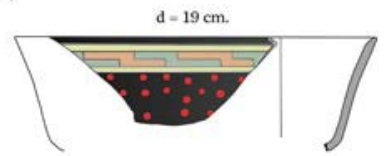

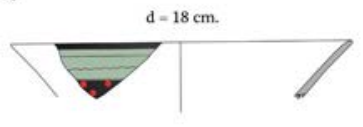

d)

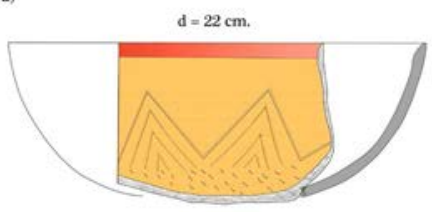

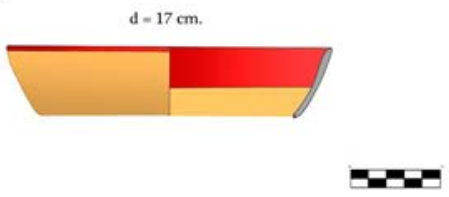

Figura 17. Reconstrucciones de tazones y cuencos Paracas Cavernas (dibujos: Alexis Rodríguez).

estructura cuadrangular (dos por dos metros y 1,80 metros de altura). Durante su proceso de excavación, pudimos distinguir dos niveles, cada uno de los cuales con un fardo funerario con ofrendas. Aunque la estructura fue saqueada antiguamente, por las evidencias de restos humanos encontrados, es posible que contuvo muchos más individuos. 


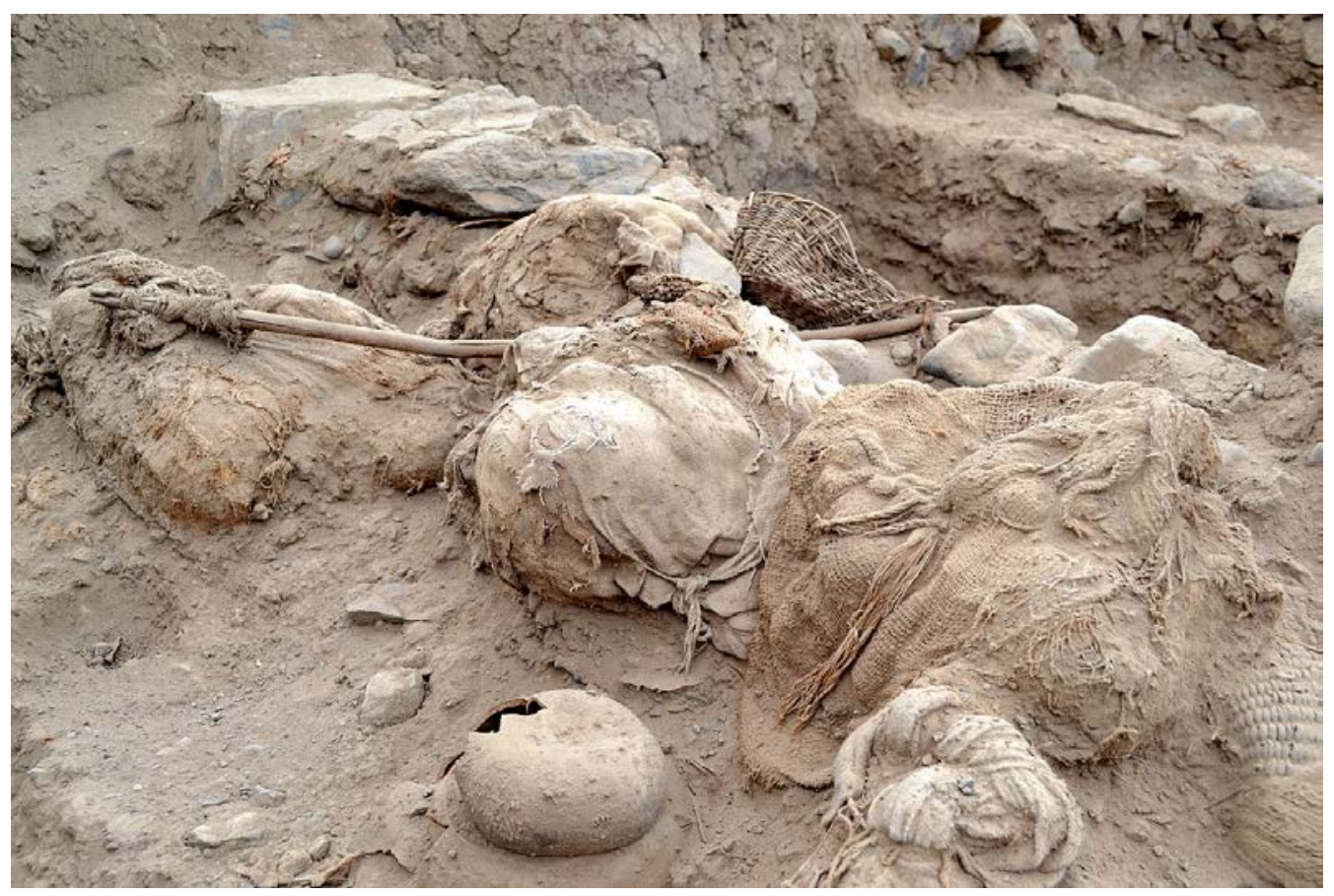

Figura 18. Vista desde el noreste de los fardos funerarios Paracas (foto: Henry Tantaleán).

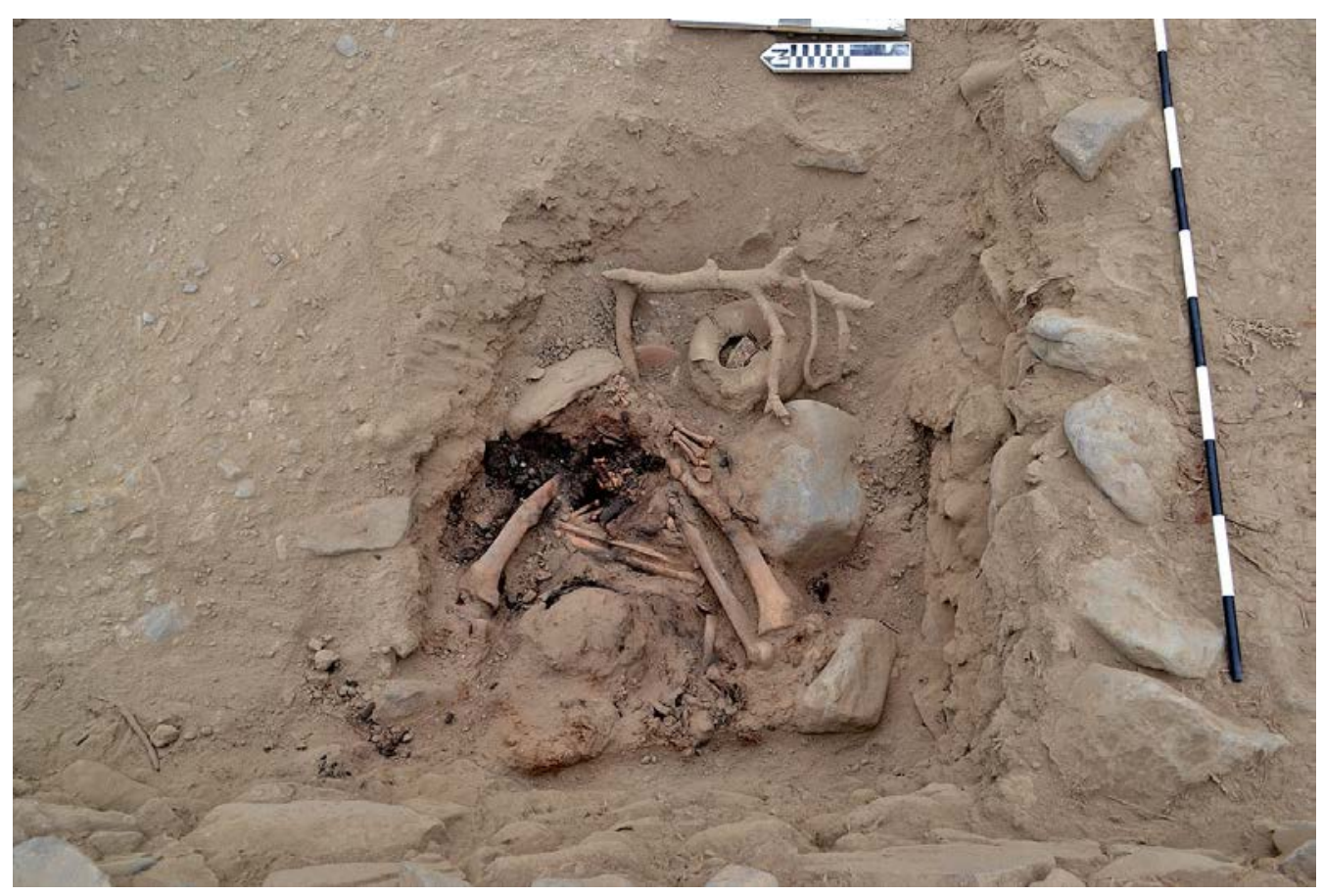

Figura 19. Vista cenital de enterramiento humano encontrado en la esquina suroeste del patio hundido de la fase gris (foto: Henry Tantaleán). 


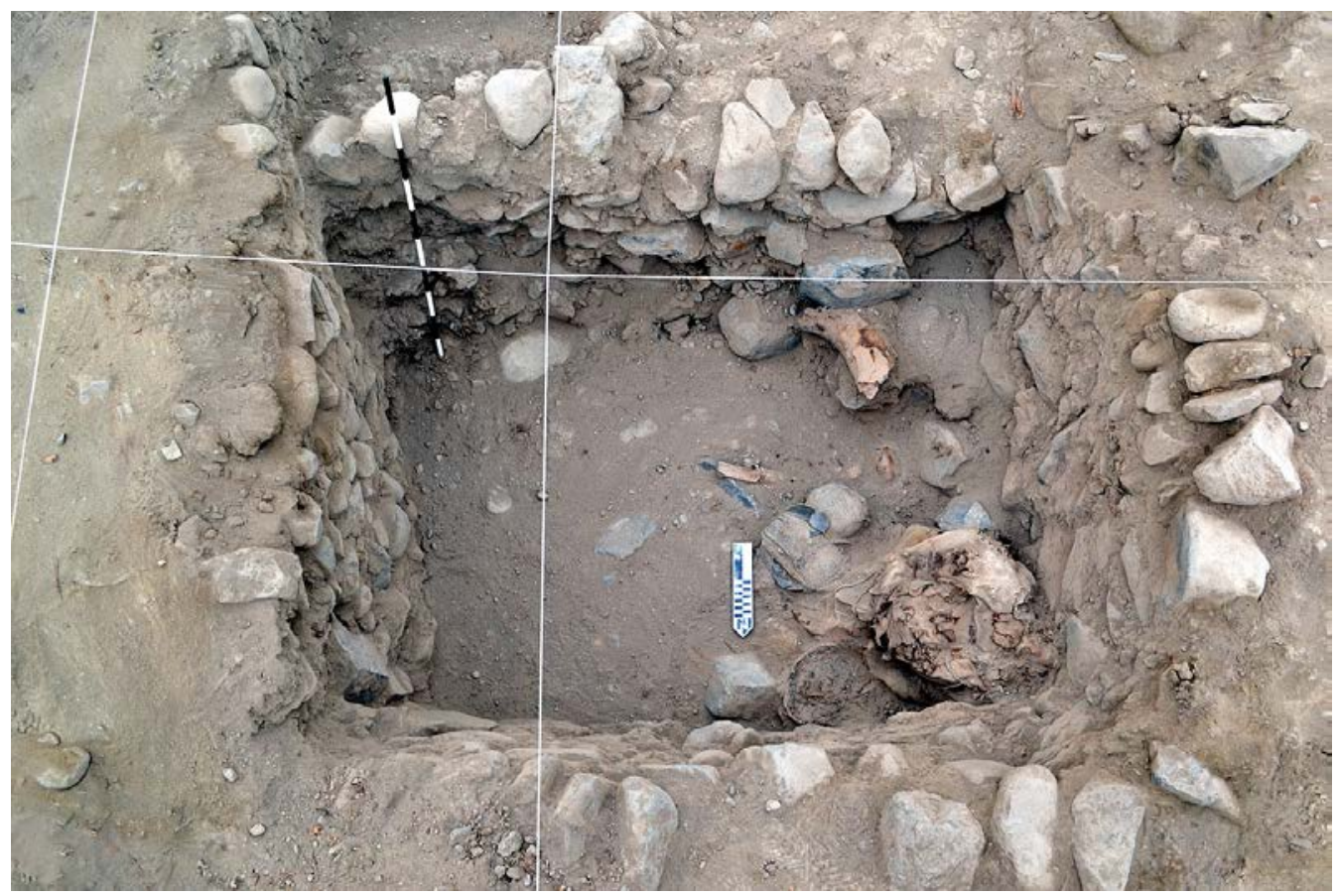

Figura 20. Vista cenital de estructura funeraria. Nótese el fardo funerario (foto: Henry Tantaleán).

3.3.1.3. Prácticas sociales durante el relleno de la fase Marrón: El proceso de enterramiento del patio hundido, y posiblemente otros recintos por parte de los dirigentes de la sociedad Paracas, se puede relacionar con el intento de generar un espacio ritual incluso en el momento mismo del abandono del edificio. Probablemente, los restos arqueológicos que hemos encontrado estén vinculados con el auspicio de fiestas en las que se reunía a gran cantidad de personas de las comunidades cercanas. Un motivo importante para esta reunión podría ser el abandono «oficial» por parte de los líderes de la sociedad Paracas del edificio de Cerro del Gentil. En general, lo que se dio durante el proceso de sellado fue lo que se conoce en la literatura antropológica y arqueológica como «ritual de terminación» o «enterramiento ritual» (Gamboa 2015). En el caso del Edificio 1 de Cerro del Gentil, varios eventos se dieron durante un lapso de tiempo que, aunque no podemos precisar, debió ser muy corto de acuerdo a la homogeneidad en la cerámica paracas encontrada y a los fechados radiocarbónicos de diferentes contextos dentro de estas capas de relleno.

Dado que el recinto FM-1 tenía la mayor profundidad durante este momento y que poseía un espacio restringido, allí se realizaron la mayor cantidad de deposiciones de artefactos y desechos. De estos depósitos, el que destaca es la Capa E por ser uno de los primeros depósitos rituales y por sus características extraordinarias. Dada la significancia de dicho contexto arqueológico, su descripción y explicación se han abordado in extensu en otro lugar (Tantaleán et al. 2016).

Con respecto a la capa de estiércol de cuy, se puede plantear que, posiblemente, este espacio más reducido se convirtió temporalmente en un corral de cuyes, que, según sabemos por los registros etnohistóricos y etnográficos, eran parte de ceremonias o ritos. Sobre dicha capa, se hallaron sucesivamente capas de tierra mezcladas con restos de plantas, especialmente conjuntos de tallos y hojas de maíz, y fragmentos de cerámica también paracas. Estas capas terminaron de cubrir el patio hundido y las áreas cercanas, como el atrio del patio. Las ofrendas encontradas serían parte del sacrificio de artefactos y animales, y los desechos de las mismas actividades rituales. 
Finalmente, durante diferentes momentos del sellado del patio, se destruyeron los recintos que rodeaban al patio hundido como los del área al oeste. Inferimos esto sobre la base del hallazgo de muchos de los bloques de piedra que formaron sus bases y paredes, y que fueron arrojados junto con otros materiales que rellenaron el patio.

3.3.1.4. Enterramiento de fardos funerarios dentro del relleno: Todos los fardos funerarios encontrados dentro del relleno guardan bastante similitud con los de la tradición Paracas Cavernas hallados en Cerro Colorado en la península de Paracas (Yacovleff y Muelle 1932; Tello y Mejía Xesspe 1979, 2005 [1959]; Tello 2009). Por tanto, el patrón de enterramiento y los materiales asociados a dichos cuerpos indican una fuerte relación con los grupos vinculados a la tradición Paracas. Además, estos entierros pertenecerían a miembros de la sociedad local con cierta importancia dentro de la jerarquía social, lo que se evidenciaría por su internamiento dentro del área más importante del edificio de Cerro del Gentil, las ofrendas asociadas y el mismo trabajo para inhumarlos allí. Sin embargo, a pesar de que un análisis bioantropológico no ofreció evidencia contundente de violencia sobre los cuerpos, no se descarta la posibilidad de que los individuos también hayan podido ser sacrificados y ofrendados a la misma huaca.

3.3.1.5. Construcción y uso de la estructura funeraria dentro del relleno del patio: En el sector noreste del relleno de la fase Marrón y del antiguo patio hundido, se definió la entrada de una estructura cuadrangular con muros de piedra unidos con argamasa de barro. Al parecer, la estructura funeraria tuvo dos momentos principales de ocupación. La primera incluyó el internamiento en el fondo de la estructura de un fardo funerario de tradición Paracas con ofrendas de mates y artefactos hechos con carrizos. El segundo momento de ocupación se relaciona con la refacción de la estructura que adosa un muro de apoyo en la base y muro sur de la estructura. Esta refacción redujo el espacio, pero posibilitó la introducción de, al menos, otros dos fardos funerarios, de los cuales solamente recuperamos uno intacto (Fig. 20). Adicionalmente, dentro de la tierra al interior de la estructura, se recolectaron restos humanos, textiles y cerámicos. La inhumación de los individuos dentro de la estructura funeraria representó uno de los últimos eventos vinculados con la ocupación paracas del Edificio 1.

\section{La ocupación topará}

\subsection{Plataforma topará}

La plataforma topará se construyó sobre la parte central del edificio de Cerro del Gentil, posiblemente, sobre el área que contenía a un segundo patio hundido (Fig. 22). Esta plataforma tiene una extensión de 20 metros en el eje este-oeste por 14 metros en el eje norte-sur. La plataforma se caracteriza por estar construida con piedras grandes y adobes hemielípticos del tipo Topará (Wallace 1986: 42; Peters 1997). Nuestras excavaciones se limitaron a la zona central de la plataforma, en la que existía un pozo de huaqueo y al extremo oeste de la plataforma muy cercano a la superposición de esta sobre el muro este del patio de la fase Gris. Para generar la plataforma, se colocaron muros de contención con grandes bloques de piedras, y rellenos de piedras y tierra. Esta primera base se elevó unos 100 centímetros sobre la cabecera original del muro este del patio hundido de la fase Gris. Sobre esta base, se construyeron muros hechos con adobes hemielípticos con su base colocada hacia el paramento externo (Fig. 23). Estos adobes hemielípticos son similares a los que describió Wallace (1986: 42) para sitios relacionados con Topará en Chincha y Pisco, así como los que hallaron Ann Peters $(1997,2013)$ y Helaine Silverman (1998) en el Complejo Alto del Molino, en la margen sur del valle bajo de Pisco, y que también estaban relacionados a la fase cerámica Chongos, perteneciente a la tradición Topará. El estado de conservación de los recintos en la parte superior de esta plataforma fue deficiente debido principalmente al intemperismo y a la erosión eólica. Un gran pozo de huaqueo en la parte central de la plataforma permitió reconocer que existieron otras estructuras subyacentes hechas con piedras canteadas. 


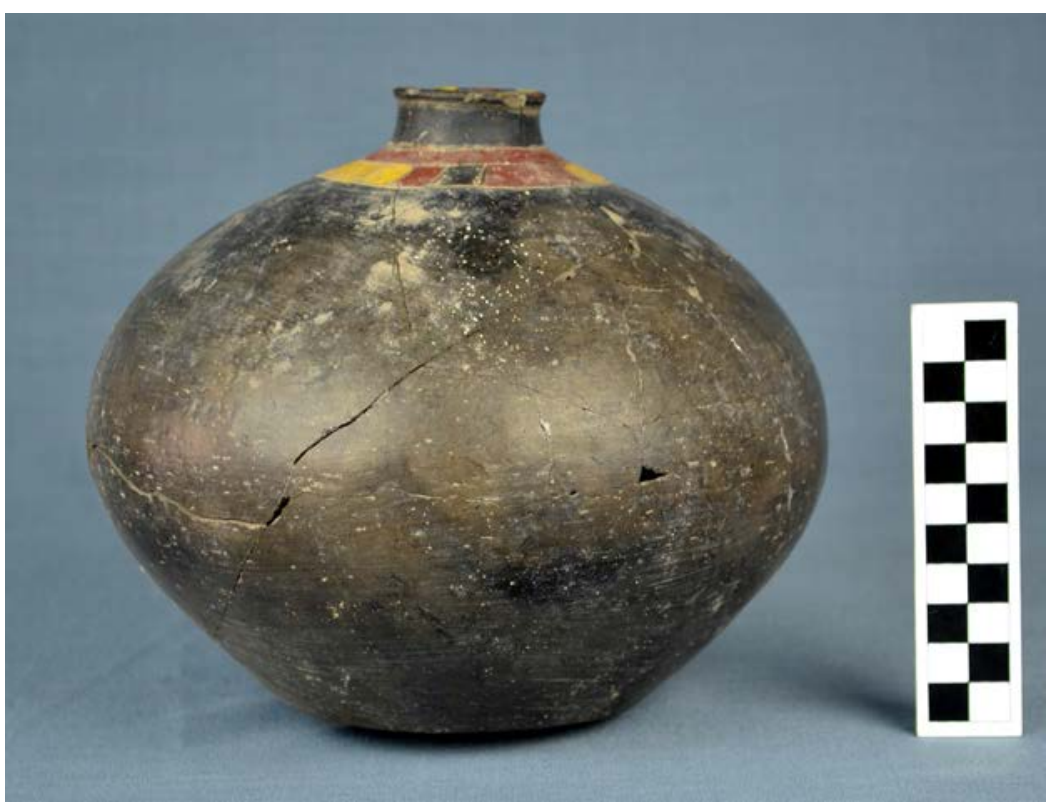

Figura 21. Vasija Paracas Cavernas reconstruida asociada al fardo recuperado en la excavación de la estructura funeraria (segundo momento) (foto: Henry Tantaleán).

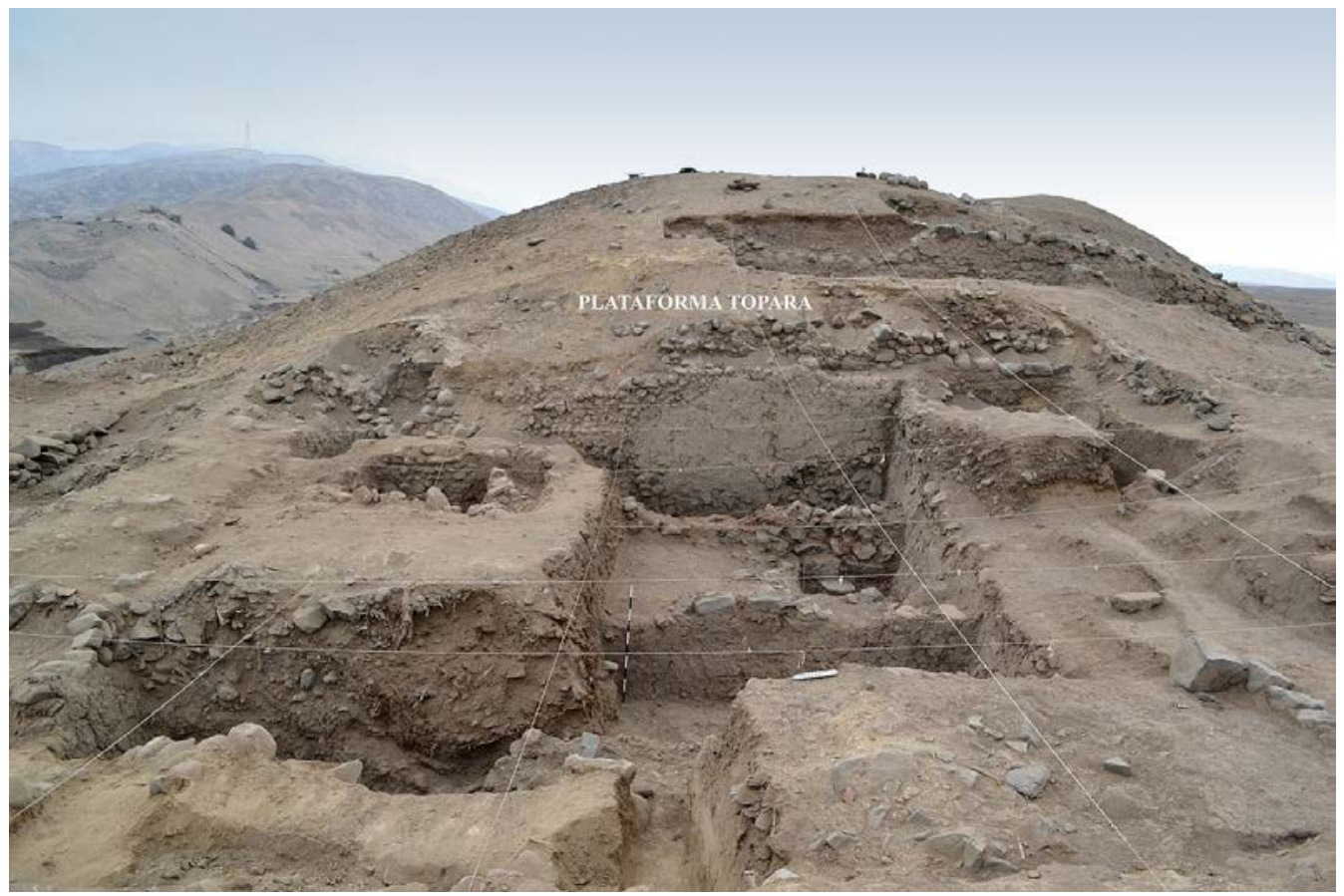

Figura 22. Vista desde el oeste de la plataforma Paracas (foto: Henry Tantaleán). 


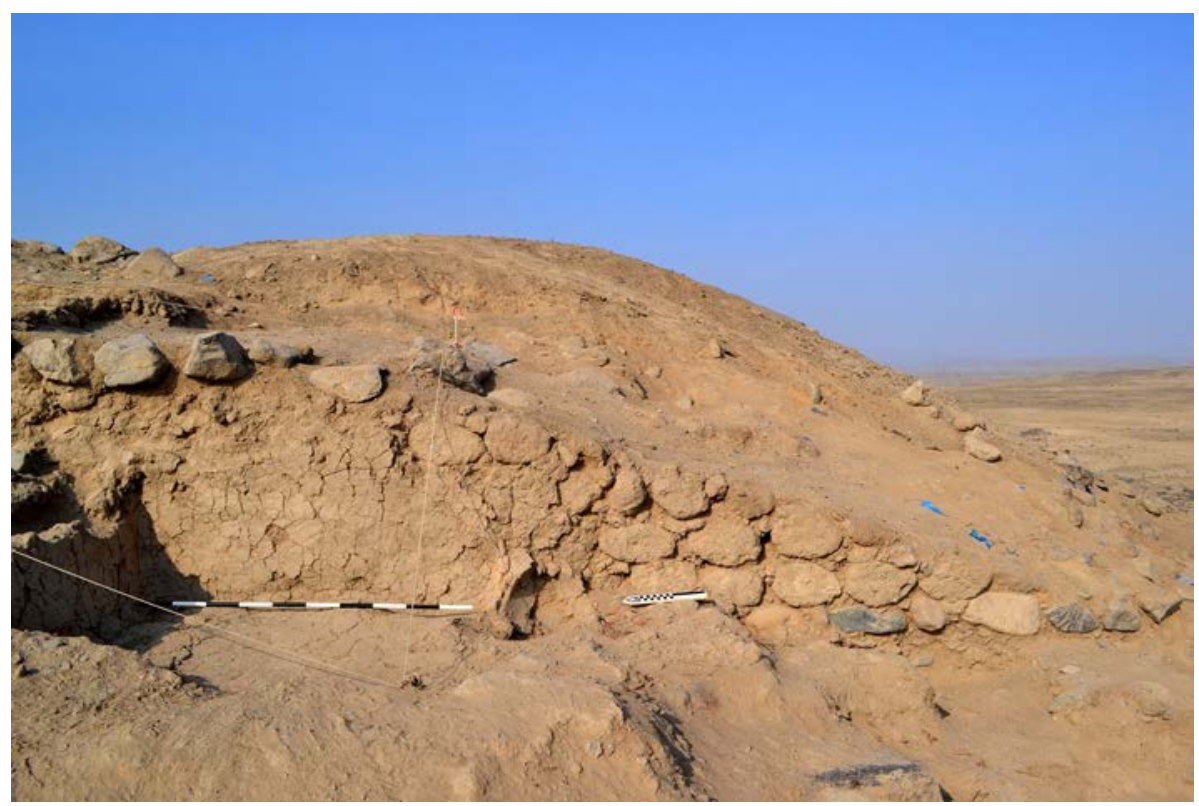

Figura 23. Vista desde el oeste del muro de adobes de estilo Topará (foto: Henry Tantaleán).

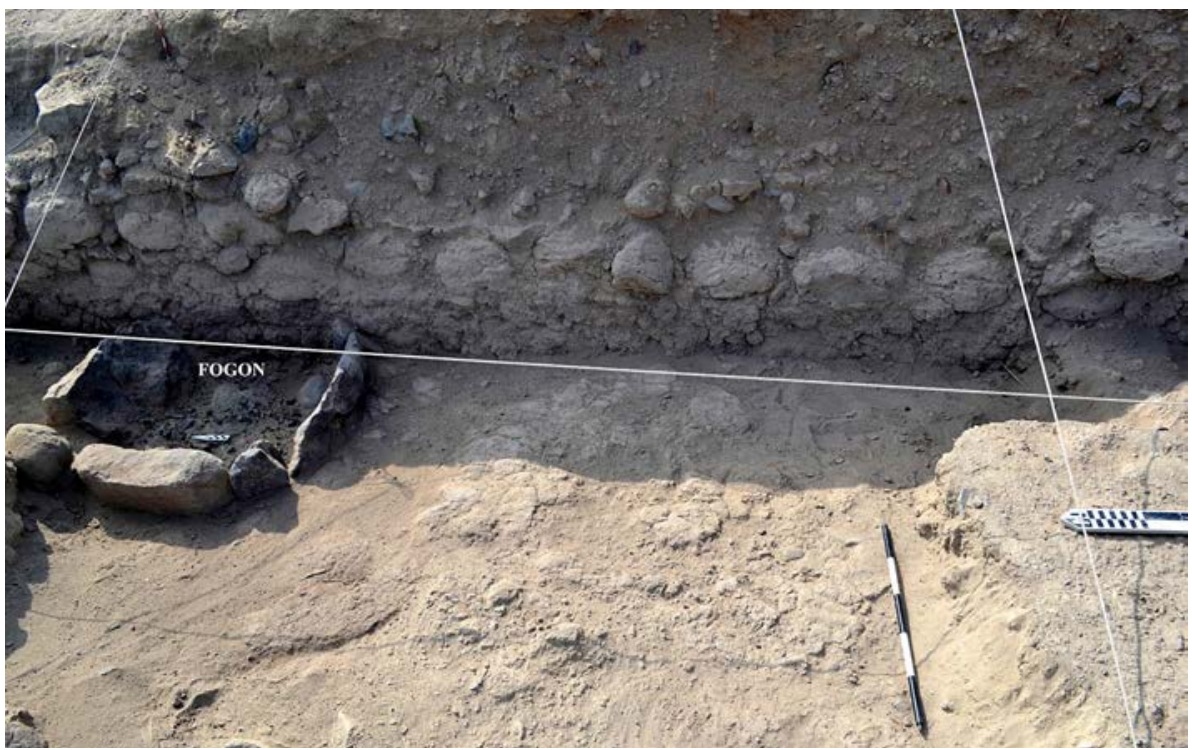

Figura 24. Fogón asociado a cerámica Topará (foto: Henry Tantaleán).

También, durante nuestras excavaciones, registramos la presencia de pequeños recintos cuadrangulares en el lado oeste de la plataforma. Estos recintos se caracterizan por presentar muros hechos con adobes hemielípticos, característicos de Topará, los cuales se encuentran enlucidos con barro. Aunque bastante erosionados, esta serie de recintos se extienden en un eje norte-sur sobre el extremo oeste de la plataforma topará, con una altura de 0,70 metros. Los recintos tienen pisos de barro preparado. Por el lado oeste, el recinto norte quedó abierto, con lo cual da la vista al sector de los anteriores patios hundidos, y un fogón hecho con grandes lajas de piedra que contiene una gran 


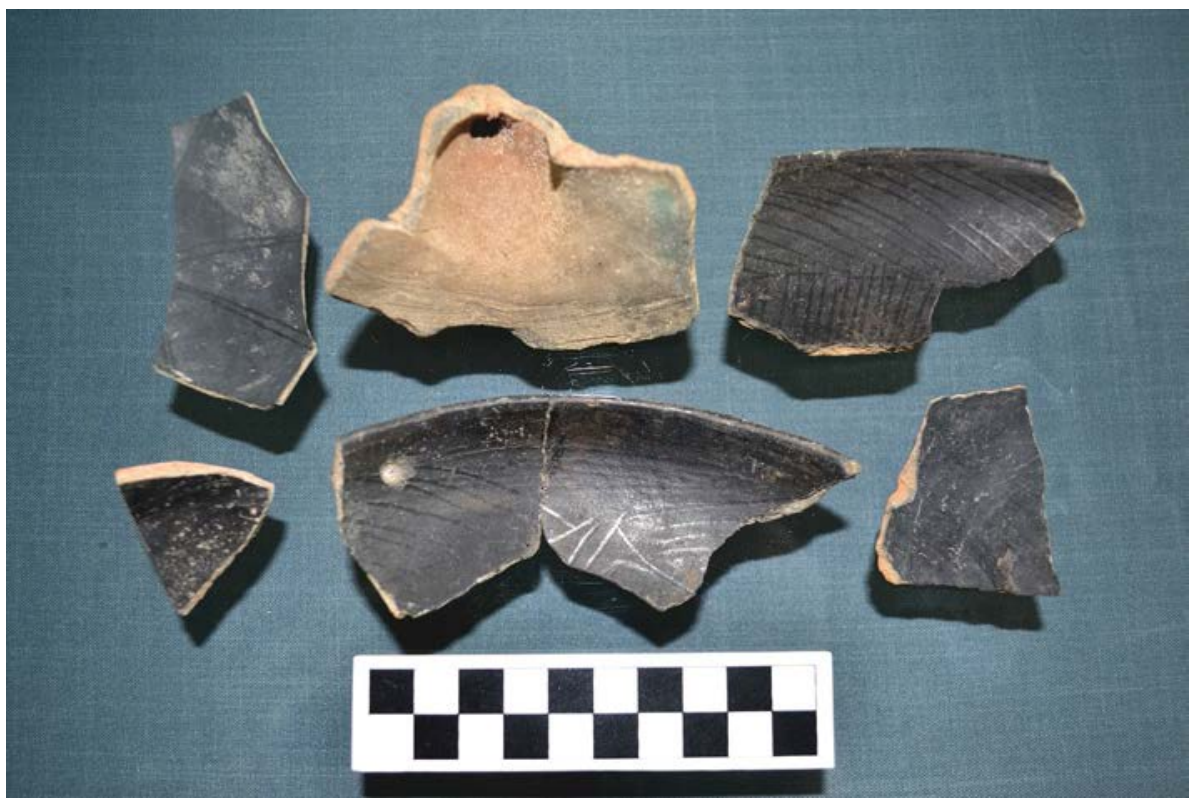

Figura 25. Fragmentos de cerámica Topará (foto: Henry Tantaleán).

cantidad de carbón (Fig. 24). Adicionalmente, en el extremo este del Edificio 1, se registraron los restos de un acceso a la parte superior de la plataforma ubicado sobre los muros paracas. Toda esta arquitectura estuvo asociada a fragmentos de cerámica topará, especialmente, la variante Chongos Blackware (Fig. 25 y 26).

\subsubsection{Prácticas sociales durante la ocupación topará}

4.1.1.1. Construcción de la plataforma topará: Luego del enterramiento total del patio hundido de Cerro del Gentil, la parte central del edificio fue utilizada para construir la plataforma topará. Esta modificación topará le agregó mayor volumen y altura a la plataforma original paracas, dándole la apariencia que posee actualmente. Sin embargo, a diferencia de la arquitectura paracas, la topará parece haberse realizado sin mayor planificación y casi de una manera expeditiva, con materiales de fácil acceso, seguramente, mediante el reciclaje de materiales del edificio paracas.

Buscar mayor altura, además del efecto de apropiación de un edificio previo con carga ritual, también ofrecería la posibilidad de tener un mayor control visual de la pampa adyacente y del valle irrigado. La dispersión en la superficie del sitio de cerámica de la fase Chongos, especialmente la variante Chongos Blackware en el área (Nigra et al. 2013), admite la posibilidad de que se hayan realizado muchas más actividades al aire libre alrededor de la plataforma que en la época Paracas. Es posible que observaciones astronómicas y otros ritos también se llevaran a cabo en la plataforma y en su exterior. Los campos de geoglifos de la pampa posiblemente siguieron estando en uso (Stanish et al. 2014).

4.1.1.2. Actividades en los recintos y parte superior de la plataforma: Respecto a los hallazgos asociados a esta estructura, registramos cerámica de la tradición topará, específicamente de la fase Chongos. De la misma manera, uno de los hallazgos más importante fue la de un fogón formal, delimitado con lajas de piedra incrustado en el piso del recinto. Los recintos, sin embargo, no presentaron mayor deposición de desechos y la existencia de un fogón de grandes dimensiones plantea que estos recintos estuvieron relacionados con actividades rituales supradomésticas, quizá vinculadas con actividades en la pampa cercana al edificio. 
a)

$\mathrm{d}=\mathbf{2 0}$

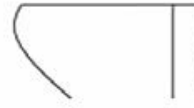

b)

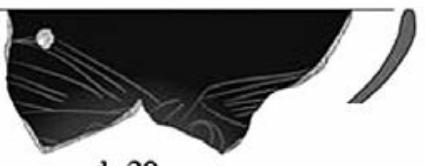

$\mathrm{d}=20$

c)

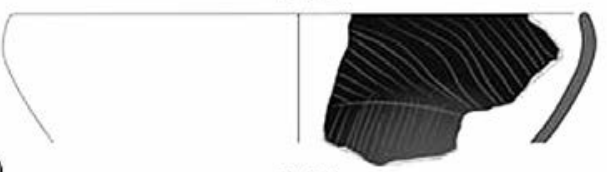

$\mathrm{d}=\mathbf{2 0}$

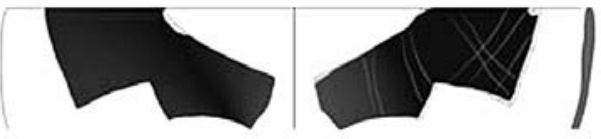

d)

$\mathrm{d}=20$

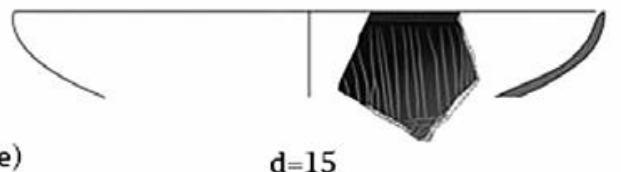

e)

$\mathrm{d}=15$

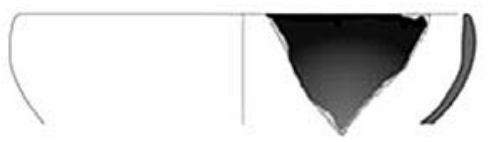

f)
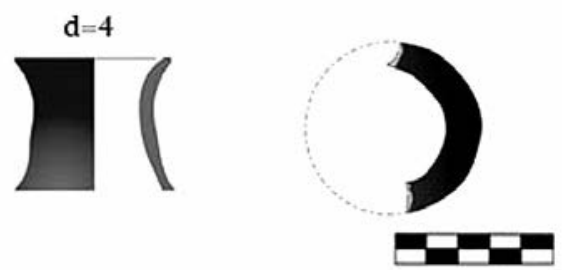

Figura 26. Reconstrucción de formas cerámicas Topará (dibujo: José Luis Tumbalobos).

\section{Discusión}

Cerro del Gentil es un sitio extraordinario en la arqueología del valle de Chincha por su ubicación, ocupaciones humanas y sus contextos arqueológicos asociados. La historia de esta huaca tiene importantes implicancias para explicar el desarrollo de Paracas en este sector del valle, así como también las ocupaciones humanas tempranas relacionadas con el surgimiento, desarrollo y caída de la arquitectura monumental en el valle de Chincha. Asimismo, nos permite reconocer la ocupación humana relacionada con el estilo Topará, cuya explicación sigue siendo aún dependiente de contextos arqueológicos disimiles y poco ilustrados.

Con respecto a la ocupación paracas en Cerro del Gentil, los edificios principales fueron fundados por grupos relacionados con el estilo arquitectónico y cerámico local relacionado con Paracas. De hecho, la tradición de edificios platafórmicos orientados en el eje oeste-este es clásica en el valle de Chincha, y señalan que todos fueron parte de un programa regional de edificios coordinados en el territorio del valle bajo y medio. El edificio de Cerro del Gentil parece haber sido fundado en el siglo VI antes de Cristo contemporáneamente al uso de los principales edificios de la 
parte baja del valle como Huaca Soto. Debido a los eventos indicados arriba, la cerámica que más se ha encontrado en el sitio pertenece a las fases tardías de Paracas y que Dwight Wallace (Wallace 1985: 69; Lanning 1960: 417) bautizó como fase Pinta. ${ }^{3}$ Las excavaciones que realizó junto a Edward Lanning, descritas en su tesis doctoral (Lanning 1960), apuntan a que la cerámica de la fase Pinta se expandió hasta prácticamente el borde del mar, encontrándolo específicamente durante sus excavaciones en el sitio de Pozuelo (PV.57-52). Por tanto, lo que se puede inferir es que existió un patrón cerámico y arquitectónico a lo largo de todo el valle de Chincha y que, incluso, apareció en contextos domésticos como el excavado en Pozuelo.

Con respecto a la ocupación paracas en el valle, es durante la ocupación asociada con Paracas Medio y Tardío cuando se dan las ocupaciones de otros edificios platafórmicos del valle, incluidos los edificios de El Mono, que mantienen patrones arquitectónicos y ceramográficos similares (Isla 1992). En la parte baja del valle, sitios monumentales como Huaca Alvarado (Uhle 1924), Huaca Santa Rosa (Kroeber 1944; Bendezú 2008) y Huaca Soto (Stanish y Pérez 2016) poseen cerámica contemporánea con la de Cerro del Gentil. Las actividades rituales serían semejantes dadas las configuraciones arquitectónicas y los espacios insertos en ellos. La cerámica morfofuncional y decorativamente también apunta a las mismas prácticas rituales.

En el caso de Cerro de Gentil, la deposición de cuerpos humanos en fardos típicos Paracas Cavernas nos ofrece la oportunidad de estudiar dichas prácticas sociales como a los mismos individuos. Las similitudes en las prácticas funerarias y los contenidos de los contextos (Tello y Mejía Xesspe 1979, 2005 [1959]; Tello 2009) nos señalan una identidad con algunos fardos encontrados en la misma tumbas paracas cavernas de la península, lo cual apoya la hipótesis de que algunos de esos fardos funerarios serían llevados desde el valle de Chincha (Lumbreras 2008).

Además de las semejanzas entre prácticas funerarias y cultura material entre Cerro del Gentil y la península de Paracas, también existen similitudes entre la cerámica encontrada en sitios de los valles de Cañete, Topará y Pisco. Así, en el valle de Cañete, el estilo cerámico Patos, definido por Wallace (1963), se correlaciona muy bien con la cerámica de las épocas tardías de Paracas, como Ocucaje 8 y 9, encontradas en Cerro del Gentil. Aunque de manera escueta, Wolfgang Wurster (1997: 16) menciona la existencia de tres sitios arqueológicos en la quebrada de Topará vinculados con la presencia de fragmentos de cerámica paracas. Asimismo, en el valle de Pisco, la cerámica encontrada por Fréderic Engel (1957) cerca de Tambo Colorado, en el Sitio 24, parece ser contemporánea con la de Cerro del Gentil.

Por otro lado, también en esta época se notan diferencias entre la cerámica paracas de Ica y la de Chincha, un aspecto ya notado por Wallace (1986). Aunque algunos diseños son similares en ambos valles, cada corpus cerámico posee sus propias particularidades locales. Es claro que existe una macrotradición paracas que se extiende entre los valles de Cańete y Nasca, pese a que cada valle parece mantener su cuota de independencia. Lo mismo se puede aplicar a la arquitectura contemporánea, por ejemplo, en el valle de Ica, donde complejos como Ánimas Altas/ Ánimas Bajas con importantes concentraciones de estructuras arquitectónicas que crean verdaderos poblados (Massey 1991; Bachir Bacha y Llanos 2013) se contraponen a sitios Paracas del valle de Chincha con poca evidencia de asentamiento permanente como en el caso de Cerro del Gentil o el Complejo El Mono.

En este punto, la arquitectura monumental y la cerámica paracas del valle de Chincha indican que existió una entidad política distinta a la de otros valles. Este estado de cosas parece mantenerse por unos tres siglos. Como señalan los episodios constructivos en Cerro del Gentil, a medida que pasó el tiempo, este orden parece degradarse y culmina con el sellado del edificio.

Tras el abandono por los líderes de los sitios como Cerro del Gentil, no se encuentran muchas evidencias de ocupaciones vinculadas con Paracas en el valle. Un caso aislado es el sitio de Pozuelo, donde Wallace y Lanning definieron el estilo San Pablo. Para nosotros, más que una fase «transicional» entre Paracas (fase Pinta) y Topará, el estilo San Pablo sería la evidencia de la supervivencia de la producción de cerámica que previamente estuvo relacionada con los rituales en los edificios paracas del valle de Chincha, pero que, posteriormente, solo se consumió en lugares habitacionales 
como Pozuelo. Esto explicaría por qué, en Cerro del Gentil, no hemos detectado la presencia de tal estilo, lo cual se debería a que este sitio fue abandonado cuando se producían las últimas muestras de cerámica incisa y decorada con pintura poscocción paracas vinculadas con la fase 9 de la secuencia de Ocucaje. En pocas palabras, la cerámica (y otros artefactos) paracas no se produjeron y consumieron desvinculados de las prácticas rituales realizadas en los edificios paracas del valle. Por tanto, el abandono de estos sitios conllevó el abandono de la producción y uso de esta cerámica.

Con respecto a la ocupación topará en el sitio de Cerro del Gentil, durante un momento brevemente posterior al abandono de los grupos afiliados a la utilización de la típica cerámica paracas, se reocupó el sitio, y se superpuso una plataforma de piedra y tierra sobre la parte central del edificio original. Al parecer, el acceso al edificio principal fue por el extremo este, en que nuestras excavaciones encontraron los restos de una escalinata construida con bloques piedra y barro. Además, sobre la plataforma, se construyeron una serie de recintos, de los cuales se conservaron de mejor manera los de la parte oeste, en los que realizamos mayores excavaciones. Se tratan de pequeños recintos, en los cuales se encontraron restos de actividades ligeras sin mayor concentración de desechos. La existencia de un fogón no doméstico, posiblemente para quemar gran cantidad de madera en su interior, confirma que posiblemente se realizaron actividades ceremoniales en la parte superior de la plataforma.

Asimismo, alrededor del sitio de Cerro del Gentil se ha recolectado una gran cantidad de cerámica de la variante Chongos Blackware (Nigra et al. 2013), lo cual apoya la hipótesis de que, durante esta ocupación, se realizaron actividades relacionadas con la arquitectura topará en Cerro del Gentil. Posiblemente, durante esta época, el sitio también funcionó asociado a los geoglifos de la pampa. También, en ese momento, otras estructuras en la misma pampa, como el sitio PV.57-61, una plataforma de piedra y barro al este de Gentil, serían parte de un complejo asociado con actividades al aire libre y desplazamientos a través de los geoglifos.

Con respecto a la presencia de otros sitios con ocupación topará cercanos, en el vecino sitio de El Mono, se han hallado reocupaciones en los edificios fundados y utilizados en época Paracas. Elizabeth Isla (1992: 25) y Luis G. Lumbreras (2008) refieren la existencia de un recinto cuadrangular con ocupación doméstica (Sector A3), ubicado al sur del edificio A2 del sitio, con presencia de cerámica topará. Por su parte, Lumbreras (1987 citado en Isla 1992: 26) encontró en sus excavaciones en el Edificio B, construido en época Paracas, evidencias de cerámica topará.

Con respecto a Pampa del Gentil, un sitio al suroeste de Cerro del Gentil, Velarde (2006) refiere el hallazgo de cerámica de tradición topará, especialmente del estilo Campana. Nuestras excavaciones restringidas también encontraron algunos fragmentos asociados a este estilo (Pérez et al. 2015). Adicionalmente, se recogió un fragmento de textil con un diseño atribuible a los textiles de la fase Paracas Necrópolis (Fig. 27).

Asimismo, contemporáneamente, el sitio de Huaca Soto en el valle bajo parece también haber tenido una ocupación similar en la que se reutilizó el patio central del edificio y se ubicaron estructuras de tipo informal sobre una gruesa capa de tierra. La cerámica chongos blackware también está presente allí (Stanish y Tantaleán 2015).

En realidad, como ya señaló Wallace (1986), la presencia de sitios con cerámica topará es escasa en el valle de Chincha. Por lo general, según lo observado por diferentes investigadores (Wallace 1986; Lumbreras 2008) y nuestro equipo, los sitios con ocupación topará, como en el caso de Cerro del Gentil, reocupan los sitios fundados en época Paracas.

Sin embargo, fuera del valle de Chincha, existen otros sitios que contienen cerámica similar a la encontrada en Cerro del Gentil. En particular, el sitio Jahuay en la quebrada de Topará contiene el mismo tipo de cerámica, especialmente la variedad cerámica chongos blackware. Más al norte, en el valle de Cañete, Wallace (1986) y Lanning (1960) reconocieron la existencia de cerámica topará en los sitios Los Patos y La Quebrada. En el valle de Pisco, posiblemente, se encuentra la mayor concentración de sitios de la tradición Topará (Peters 2013). De todos ellos, el sitio Chongos en la margen sur del valle es el de mayor extensión, y con cerámica y arquitectura topará similar a las encontradas en Cerro del Gentil (Peters 1987-1988, 1997). La misma correlación de cultura 


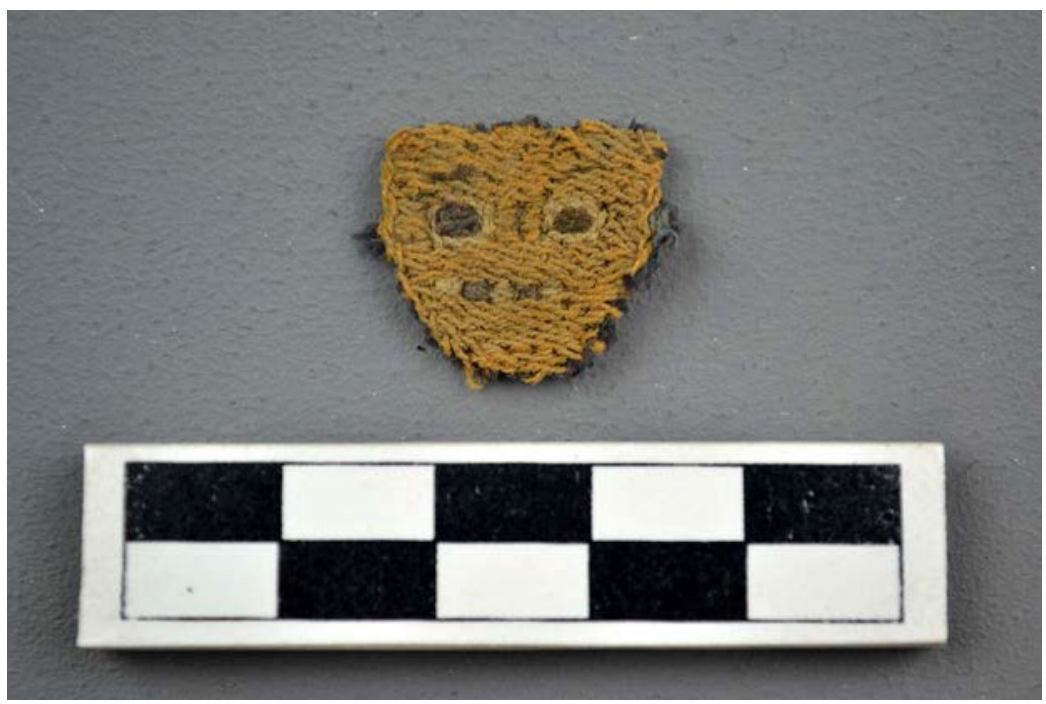

Figura 27. Fragmento textil de tradición Paracas Necrópolis excavado en Pampa del Gentil (foto: Henry Tantaleán).

material se encuentra en el Complejo Alto del Molino del mismo valle (Peters 1986, 1997, 2013; Silverman 1994: 378, 1998).

Del mismo modo, como ya ha sido discutido por otros investigadores (Wallace 1986; Peters 1997), algunos fardos de Paracas Necrópolis también están asociados con cerámica de la tradición Topará (Tello 2005 [1959]). Incluso, se ha advertido la presencia de cerámica topará en el alejado valle de Ica.

Como vemos, la distribución del estilo Topará es bastante extensa; llega incluso hasta la cuenca de Ica. Según Wallace (1986), esta dispersión de la cerámica topará fue consecuencia de una invasión de grupos humanos relacionados con esta cerámica procedentes desde el norte, posiblemente del valle de Cańete o la misma quebrada de Topará. Incluso, para Wallace (1986: 46) y Lanning (1967: 121), la distribución de este estilo en los valles de Cañete, Chincha y Pisco sería la consecuencia de la expansión de un estado. Sin embargo, esta hipótesis, como ya señaló Helaine Silverman (2009: 462), en la actualidad, cuenta con poco sustento empírico. De hecho, es posible afirmar que, por el momento, ningún otro sitio en los valles de Cañete, Topará, Chincha conocido relacionado con la cerámica topará compite en dimensiones y cultura material con el sitio de Chongos en Pisco. De esta manera, por el momento, el valle de Pisco es el mejor candidato para el surgimiento y mayor desarrollo de la tradición Topará en la costa sur.

\section{Comentarios finales}

El valle de Chincha se ha mantenido en una situación marginal en relación con las discusiones sobre la naturaleza, desarrollo e implicancias económicas, políticas e ideológicas de las culturas Paracas y Topará (Massey 1991; Paul [ed.] 1991; Silverman 1991, 1996, 2009). Pese a que una serie de estudiosos realizaron investigaciones en este valle (Uhle 1924; Kroeber 1944; Lanning 1960; Wallace 1971; Canziani 1992, 2009; Lumbreras 2008), muchas de sus representaciones arqueológicas estuvieron basadas en materiales que fueron escasamente conocidos. Asimismo, casi todo el armazón cronológico estuvo basado en secuencias estratigráficas y seriaciones cerámicas que utilizaban correlaciones entre sitios con diferentes naturalezas ocupacionales y deposicionales (Lanning 1960; Wallace 1985, 1986; Carrillo 2009), de tal manera que no existía una imagen realista de las ocupaciones humanas en el valle. Asimismo, los fechados radiocarbónicos eran inexistentes para 
las ocupaciones paracas o topará en este valle. Por tal motivo, en las discusiones sobre estas sociedades, pese a la monumentalidad de los edificios paracas, el valle de Chincha siempre se mantenía dependiente del desarrollo de las investigaciones arqueológicas en otros valles como el de Ica; la península de Paracas; o, incluso, del mismo sitio de Jahuay en la quebrada de Topará.

Creemos que el corpus de datos que venimos construyendo ayudará a cambiar sustantivamente la perspectiva de las sociedades tempranas en Chincha. En este punto de nuestras investigaciones, va quedando claro que lo que sucedió en el valle de Chincha fue que, alrededor del siglo VI a.C., se dio el surgimiento de una entidad política que tenía su propia historia de formación y particularidades. Este desarrollo no fue un obstáculo para generar contactos con sus pares del norte y del sur. Posiblemente, un lugar en el cual estas influencias e interacciones fueron mucho más dinámicas se dio a través de los espacios funerarios-rituales de la península de Paracas.

De la misma manera, observamos que lo Topará también tuvo una serie de características y que, por lo menos, en el caso de Cerro del Gentil, el sitio fue modificado y se realizaron reuniones alrededor del sitio que consumieron grandes cantidades de cerámica, similares a las que se encuentran en Pisco, Topará y la península de Paracas. Por otro lado, no queda clara la ubicación de las áreas domésticas y la construcción de nuevos edificios durante esta época, si es que los hubo. Saliendo del esquema normativo de las culturas, un importante desafío será comprender qué sucedió con las comunidades humanas vinculadas con Paracas tras la caída del sistema político que incluía a sitios como Cerro del Gentil y otros del valle se construyeron. Además, será importante comprender cómo estas comunidades se adaptaron a las nuevas situaciones históricas, y cómo y por qué adoptaron, crearon o usaron la nueva cultura material que conocemos como Topará.

Creemos que todos estos nuevos escenarios y preguntas que van surgiendo durante nuestra investigación en el valle de Chincha cambiarán nuestra forma de ver a los fenómenos paracas y topará, ya no como entidades homogéneas, sino, más bien, como comunidades involucradas en la construcción dinámica de un paisaje político y económico desigual, con sus propias historias particulares, que valen la pena ver en profundidad en los siguientes ańos.

\section{Agradecimientos}

Los autores agradecen a los Cotsen Endowments del Cotsen Institute of Archaeology de UCLA, al Institute for Field Research (IFR), a la National Geographic Society y a la National Science Foundation. Agradecimientos especiales por su apoyo económico van para Harris Bass, Bruce Hector y Charles Steinmetz.

Agradecemos al Ministerio de Cultura del Perú por los permisos y la supervisión de nuestro trabajo. Asimismo, hacemos un reconocimiento especial por su apoyo a Rubén García en su desempeño como representante de la Dirección Desconcentrada del Ministerio de Cultura en Ica. Asimismo, agradecemos a Luka Baraka y al ingeniero Luis García de la Compañía Agroexportadora Virgen del Rosario, quienes generosamente apoyaron y permitieron nuestra investigación en los terrenos adyacentes a su propiedad.

\section{Notas}

${ }^{1}$ Definimos como Paracas a la tradición arquitectónica, cerámica y textil relacionada con los materiales descubiertos por Julio C. Tello en los cementerios de Cerro Colorado. En el caso del valle de Chincha, se vincula con la tradición de edificios hechos con adobes de barro y piedras de forma rectangular con patios hundidos. La cerámica está decorada con incisiones y pintura poscocción y decoración en negativo.

${ }^{2}$ Definimos como Topará a la tradición arquitectónica, cerámica y textil que tempranamente fue descrita por Julio C. Tello como Paracas Necrópolis en la península del mismo nombre. A pesar de que existe un debate sobre su naturaleza, asumimos la existencia de Topará en el valle de Chincha como una ocupación humana consistente que se superpone físicamente a la Paracas Cavernas. 
Su arquitectura se caracteriza por utilizar adobes hemielípticos de mayor tamaño y diferente disposición que los Cavernas. La cerámica más diagnóstica es la definida por Peters (1997) como Chongos Blackware, en la que resalta la cocción de la vasija en atmósfera reductora y decoración de patrones bruñidos.

${ }^{3}$ La procedencia del lote cerámico con el cual Wallace definió la fase Pinta casi siempre se vincula con el sitio PV.57-63, el sitio conocido como El Mono o Chococota (Lanning 1960: 417, Wallace 1986: 69, Silverman 2009: 489). Sin embargo, también es posible que el sitio haya sido el mismo Cerro del Gentil (Wallace 1972, Isla 1992: 21, Lumbreras 2008). Pese a ello, como nuestras investigaciones han comprobado, ambos sitios cercanos también fueron contemporáneos durante el Período Paracas Tardío y compartieron fuertes similitudes en su corpus cerámico.

\section{REFERENCIAS}

\section{Bachir Bacha, A. y D. Llanos}

2013 ¿Hacia un urbanismo paracas en Ánimas Altas/Ánimas Bajas (Valle de Ica)?, en: A. Bachir Bacha y J. Dulanto Brescia (eds.), Paracas: nuevas evidencias, nuevas perspectivas, Boletín de Arqueología PUCP 17, 169-204.

Bendezú, O.

2008 Informe final de evaluación Arqueológica de la Huaca Santa Rosa, Chincha Baja, Chincha, informe presentado al Instituto Nacional de Cultura, Ica.

Canziani, J.

1992 Arquitectura y urbanismo del Periodo Paracas en el valle de Chincha, Gaceta Arqueológica Andina 22, 87-117.

2009 Ciudad y territorio en los Andes: Contribuciones a la Historia del urbanismo prehispánico, Fondo Editorial de la Pontificia Universidad Católica del Perú, Lima.

Carrillo, H.

2009 La presencia topará en el valle de Lurín, en R. Burger y K. Makowski (eds.), Arqueología del Periodo Formativo en la cuenca baja de Lurín, 319-329, Pontificia Universidad Católica del Perú, Lima.

Engel, F.

1957 Early sites in the Pisco Valley of Peru: Tambo Colorado, American Antiquity 23 (1), 34-45. https://doi. org/10.2307/277278

Gamboa, J.

2015 Dedication and termination ritual in southern Moche public architecture, Latin American Antiquity 26 (1), 87-105. https://doi.org/10.7183/1045-6635.26.1.87

Isla, E.

1992 La cultura Paracas dans le site archeologique «El Mono-Edifice C1», Chincha-Perou, memoria de Diploma de Estudios Avanzados, U.F.R. d'Histoire del'Art et d'Archeologie, Universite de Paris I, Pantheon-Sorbonne, París.

Kroeber, A.

1944 Peruvian archeology in 1942, Viking Fund Publications in Anthropology, Number 4, New York.

Lanning, E.

1960 Chronological and cultural relationships of early pottery styles in ancient Peru, tesis de doctorado, Department of Anthropology, University of California, Berkeley.

1967 Peru before the Incas, Prentice-Hall, New Jersey.

Lumbreras, L. G.

2008 La presence de Paracas a Chincha, en: D. Lavallée (ed.), Paracas. trésors inédits du Perou ancient, 34-39, Musee du Quai Branly, París.

Massey, S.

1991 Paracas, en: Los incas y el antiguo Perú. 3000 años de historia, 230-241, Sociedad Estatal Quinto Centenario, Madrid. 
Mujica, E.

1991 Pukara: Una sociedad compleja temprana en la cuenca norte del Titicaca, en: Los incas y el antiguo Perú. 3000 Años de Historia, 272-297, Sociedad Estatal Quinto Centenario, Madrid.

Nigra, B., K. Hill, C. Tolman, C. Weinberg y M. Rosales

2013 An analysis of surface ceramics from Cerro del Gentil: an Early Horizon mound site in the Chincha Valley, Peru, ponencia presentada en la 78a Reunión Anual de la SAA, Honolulu.

Paul, A. (ed.)

1991 Paracas. art and architecture: Object and context in south coastal Peru, University of Iowa Press, Iowa City.

Pérez, K., A. Fernández, H. Tantaleán y C. Stanish

2015 El estilo cerámico Carmen y su presencia en el valle medio de Chincha, costa sur del Perú, Bulletin de l'Institut Français d'Études Andines 44 (2), 181-204. https://doi.org/10.4000/bifea.7555

Peters, A.

1987- $\quad$ Chongos: sitio Paracas en el valle de Pisco, Gaceta Arqueologica Andina 16, 30-34.

1988

1997 Paracas, Topará and Early Nasca: ethnicity and society on the south central Andean coast, tesis de doctorado, Departamento de Antropología, Cornell University, Ithaca.

2013 Topará en Pisco: patrón de asentamiento y paisaje, en: A. Bachir Bacha y J. Dulanto Brescia (eds.), Paracas: nuevas evidencias, nuevas perspectivas, Boletín de Arqueología PUCP 17, 77-101.

Silverman, $\mathrm{H}$.

1991 The Paracas problem. Archaeological perspectives, en: A. Paul (ed.), Paracas. art and architecture: object and context in south coastal Peru, 349-415, University of Iowa Press, Iowa City.

1994 Paracas in Nazca: new data on the Early Horizon occupation of the Rio Grande de Nazca Drainage, Peru, Latin American Antiquity 5 (4), 359-382. https://doi.org/10.2307/971822

1996 The Formative Period on the South Coast of Peru: a critical review, Journal of World Prehistory 10 (2), 95-146. https://doi.org/10.1007/BF02221074

1998 The first field season of excavations at the Alto del Molino site, Pisco Valley, Peru, Journal of Field Archaeology 24, 441-457.

2009 Comparaciones y contrastes entre la costa sur y la costa central del Perú durante el Periodo Formativo, en: R. Burger y K. Makowski (eds.), Arqueología del Periodo Formativo en la cuenca baja de Lurín, 429-490, Pontificia Universidad Católica del Perú, Lima.

Stanish, C. y H. Tantaleán

2015 Informe de campo e informe final: Proyecto de Investigación Arqueológica Excavaciones en Cerro del Gentil y el Complejo Soto, valle medio y bajo de Chincha, Ministerio de Cultura del Perú, Lima.

Stanish, C., H. Tantaleán, B. Nigra y L. Griffin

2014 A 2300 year old architectural and astronomical complex in the Chincha Valley, Perú, Proceedings of the National Academy of Sciences 111 (20), 7218-7223. https://doi.org/10.1073/pnas.1406501111

Stanish, C. y K. Pérez

2016 Informe de campo e informe final: Proyecto de Investigación Arqueológica Excavaciones en el Complejo Soto, valle bajo de Chincha, Ministerio de Cultura del Perú, Lima.

Tantaleán, $\mathrm{H}$.

2016 Paisajes rituales y políticos paracas en el valle de Chincha, costa sur del Perú, Latin American Antiquity 27 (4), 479-496. https://doi.org/10.7183/1045-6635.27.4.479

Tantaleán, H., C. Stanish, A. Rodríguez y K. Pérez

2016 The final days of Paracas in Cerro del Gentil, Chincha Valley, PLoS ONE 11 (5), recuperado de http:// journals.plos.org/plosone/article?id=10.1371/journal.pone.0153465. https://doi.org/10.1371/journal. pone. 0153465

Tantaleán, H., C. Stanish, M. Zegarra, K. Pérez y B. Nigra

2013 Paracas en el valle de Chincha: nuevos datos y explicaciones, en: A. Bachir Bacha y J. Dulanto Brescia (eds.), Paracas: nuevas evidencias, nuevas perspectivas, Boletin de Arqueología PUCP 17, 31-56.

Tello, J. C.

2009 Paracas Cavernas, Cuadernos de investigación del Archivo Tello, Museo de Arqueología y Antropología de la Universidad Nacional Mayor de San Marcos, Lima. 
Tello, J. C. y T. Mejía Xesspe

1979 Paracas. Segunda parte: Cavernas y Necrópolis, Universidad Mayor de San Marcos/Institute of Andean Research de Nueva York, Lima.

2005 Paracas. Primera parte, Empresa Grafica, Lima.

[1959]

Uhle, $M$.

1924 Explorations at Chincha, University of California Publications in American Archaeology and Ethnology 21 (2), 57-94, Berkeley.

Velarde, L.

2006 El Intermedio Temprano en el valle de Chincha (Peru): El sitio de Pampa del Gentil, en: H. Yacobaccio, D. Olivera, S. Purin y R. Miller (eds.), Acts of the XIVth UISPP Congress, University of Liège, Belgium, 2-8 September 2001, Section 17: American Prehistory: General Sessions and Posters: C17.1: Change in the Andes: origins of social complexity, pastoralism and agriculture, 171-181, British Archaeological Reports International Series 1524, Archaeopress, Oxford.

Wallace, D.

1963 Early Horizon ceramics in the Cañete Valley of Peru, Nawpa Pacha 1, 35-38. https://doi.org/10.1179/ naw.1963.1.1.003

1971 Sitios arqueológicos del Perú (segunda entrega): valles de Chincha y de Pisco, Arqueológicas 13, Lima.

1972 Sumario de la secuencia cultural de los valles de Chincha y Pisco, manuscrito.

1985 Paracas in Chincha and Pisco: A Reappraisal of the Ocucaje Sequence, en: P. Kvietok y D. Sandweiss (eds.), Recent studies in Andean prehistory and protohistory, 67-94, Latin American Studies Program, Cornell University, Ithaca.

1986 The Topara tradition: an overview, en: D. Sandweiss y P. Kvietok (eds.), Perspectives on Andean prehistory and protohistory, 35-48, Latin American Studies Program, Cornell University, Ithaca.

Yacovleff, E. y J. C. Muelle

1932 Una exploración en Cerro Colorado. Informe y observaciones, Revista del Museo Nacional 1 (2), 31-59.

Wurster, Wolfgang

1997 Desarrollo del urbanismo prehispánico en el valle de Topará, Costa Sur del Perú, en: E. Bonnier y H. Bischof (eds.), Arquitectura y Civilización en los Andes Prehispánicos; Archaeologica Peruana, 2, 12-27, Reiss-Museum, Mannheim. 